\title{
Synthesis and Supramolecular Functional Assemblies of Ratiometric pH Probes
}

Alejandro Méndez-Ardoy Jose Juan Reina, Javier Montenegro

\section{Accepted Author Manuscript}

This is the peer reviewed version of the following article: CMéndez-Ardoy, A., Reina, J..J. and Montenegro, J. (2020), Synthesis and Supramolecular Functional Assemblies of Ratiometric $\mathrm{pH}$ Probes. Chem. Eur. J., which has been published in final form at https:// doi.org/10.1002/chem.201904834. This article may be used for non-commercial purposes in accordance with Wiley Terms and Conditions for Use of Self-Archived Versions

\section{How to cite:}

Méndez-Ardoy, A., Reina, J..J. and Montenegro, J. (2020), Synthesis and Supramolecular Functional Assemblies of Ratiometric pH Probes. Chem. Eur. J. doi:10.1002/chem.201904834

\section{Copyright information:}

(C) 2020 WILEY-VCH Verlag GmbH \& Co. KGaA, Weinheim. This article may be used for noncommercial purposes in accordance with Wiley Terms and Conditions for Use of SelfArchived Versions 


\section{Synthesis and Supramolecular Functional Assemblies of Ratiometric pH Probes}

Dr. Alejandro Méndez-Ardoy, ${ }^{[\mathrm{a}]^{*}}$ Dr. Jose J. Reina ${ }^{[\mathrm{a}]}$ and Dr. Javier Montenegro, ${ }^{\left[\mathrm{a}{ }^{\star}\right.}$

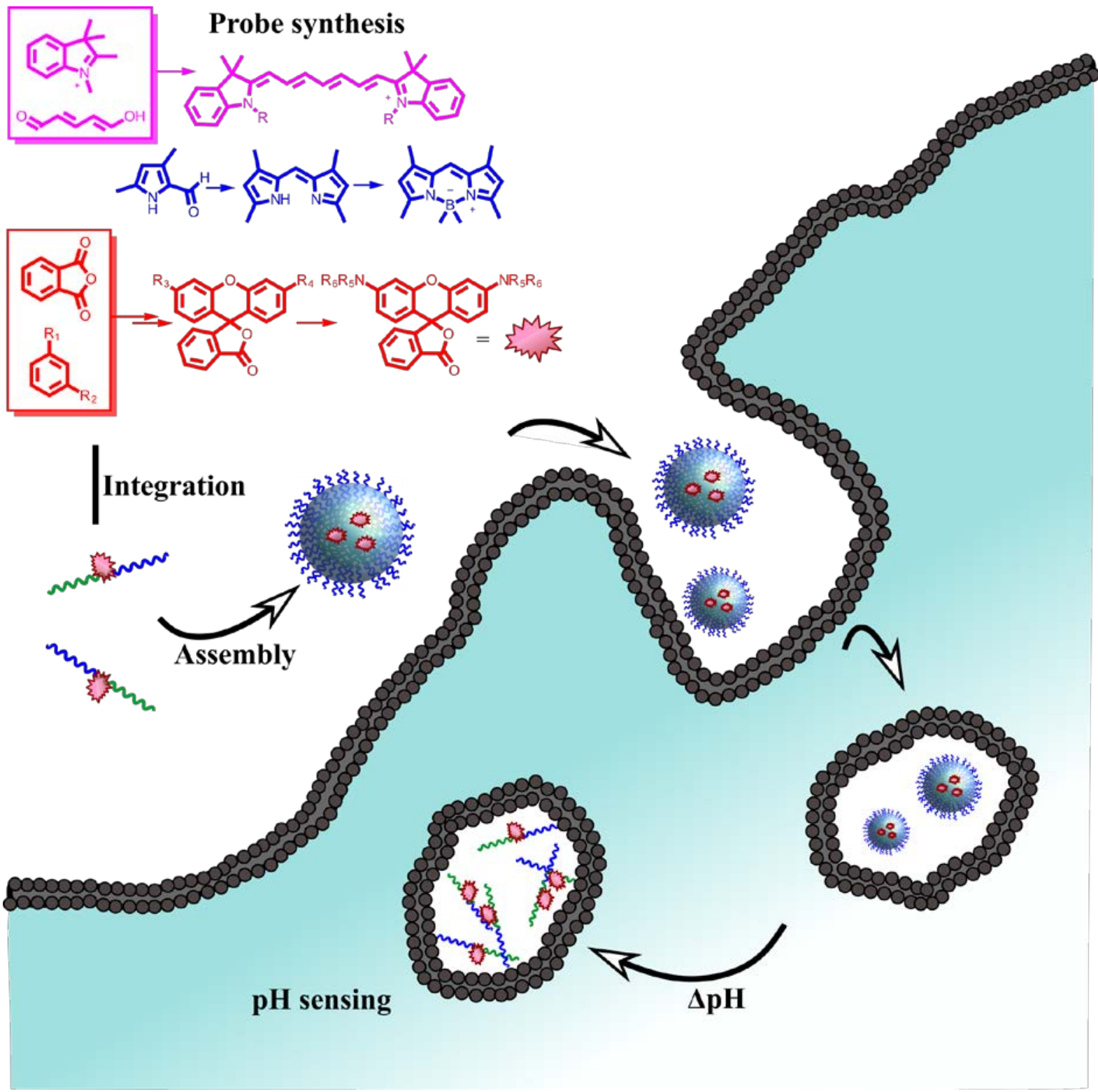

a Centro Singular de Investigación en Química Biolóxica e Materiais

Moleculares (CIQUS), Departamento de Química Orgánica,

Universidade de Santiago de Compostela, 15782 Santiago de

Compostela, Spain. *e-mail: alejandro.mendez@usc.es; *e-mail:

javier.montenegro@usc.es

Supporting information for this article is given via a link at the end of the document.((Please delete this text if not appropriate)) 
Abstract: Tracking the $\mathrm{pH}$ with spatiotemporal resolution is a critical challenge for synthetic chemistry, chemical biology and beyond. Over the last decade different small probes and supramolecular systems have emerged for in cellulo or in vivo $\mathrm{pH}$ tracking. However, $\mathrm{pH}$ reporting still presents critical limitations such as background reduction, sensor improved stability, cell targeting, endosomal escape, near and far infrared ratiometric $\mathrm{pH}$ tracking, adaptation to the new imaging techniques (i.e. super-resolution), etc. These challenges will demand the combined efforts of synthetic and supramolecular chemistry working together to develop a next generation of smart materials that will resolve the current limitations. In this review we describe the recent advances in the synthesis of small fluorescent probes together with new supramolecular functional systems employed for $\mathrm{pH}$ tracking with emphasis in ratiometric probes. The combination of organic synthesis and stimuli-responsive supramolecular functional materials will be essential to solve future challenges of $\mathrm{pH}$ tracking such as the improved signal to noise ratio, on target activation and microenvironment reporting.

\section{Introduction}

Fluorescent molecules are important chemical probes to study and manipulate biological systems. ${ }^{[1]}$ Fluorophores can currently be classified into three general groups: organic dyes, biological fluorophores and quantum dots. ${ }^{[2]}$ Synthetic organic dyes were one of the first chemical probes applied to study cellular functions. Fluorescent proteins were later introduced to label proteins by fusion techniques, ${ }^{[3]}$ which allowed time-resolved fluorescent tracking of endogenous biological processes. Much has been discovered with the application of fusion techniques with fluorescent proteins and related methodologies. ${ }^{[4]}$ However, small molecular fluorophores are still preferred when labelling exogenous biomolecules and to homogeneously distribute the probe inside cells or tissues. Quantum dots and protein luminophores are relative big molecules and when administered exogenously they suffer for several size-related problems such as aggregation or precipitation, endosomal entrapment, toxicity, etc. ${ }^{[1]}$

In principle, molecular probes can be applied to any sample, including tissues, they are relatively inexpensive and easier than to handle and they can generally provide high signal-to-noise ratios as a result of ingenious chemical design. ${ }^{[5]}$ Therefore, small molecular probes will always be there as fundamental fluorescent signal generators that can work alone or in combination with other macro and supramolecular entities. Furthermore, small fluorophores can be easily attached to biomacromolecules (i.e. enzymes, nucleic acids, antibodies, etc.) with minimal impact over the desired biological function. The structural diversity of the current available palette of fluorescent molecules allows the selection of customized probes for particular applications. ${ }^{[6]}$ Therefore, the particular properties of each fluorescent molecule should be carefully considered for each application or experimental system.

In biology, $\mathrm{pH}$ sensitive ratiometric fluorophores are of strong interest, as they can report with spatiotemporal resolution on the $\mathrm{pH}$ inside cells and tissues and this $\mathrm{pH}$ differences can be correlated with intracellular distribution and/or cell machinery malfunction. ${ }^{[7]}$ An example is illustrated in Fig. 1. Ratiometric fluorescent probes generally present absorption or emission intensity variations at two well-differentiated wavelengths, which is dependent on changes of the environmental conditions (e.g. $\mathrm{pH})$. The presence of two fluorescence signals allows selfcalibration, and therefore changes in intensity due to experimental artefacts such as dilution or quenching are circumvented, yielding more accurate measurements (Table 1). Certain ratiometric $\mathrm{pH}$ sensitive fluorescent dyes are commercially available at small scale, which strongly hinder their synthetic implementation in man-made artificial fluorescent biosensors. This synthetic limitation hampers the promising combination of ratiometric fluorophores with stimuli responsive macromolecular assemblies, nanomachines and the next generation of smart biosensors. Nevertheless, the preparation of many of these ratiometric fluorescent small molecules can be achieved by simple synthetic protocols, at sufficient scale and without the requirement of sophisticated equipment. In addition, the recent advances in stimuli responsive supramolecular systems have triggered the emergence of a new range of conceptual imaging protocols for the precise tracking of complex intracellular processes. Therefore, the combination of improved small fluorescent probes together new supramolecular functional systems will be of fundamental importance to solve the future challenges in bioimaging such as reduced background signal, on target activation and microenvironment reporting. By merging the strengths of supramolecular chemistry and the total synthesis of molecular probes, chemists will develop the next generation of smart and precise imaging probes with improved physicochemical properties such as $\mathrm{pH}$ range, quantum yield, photobleaching, etc. Therefore, the objective of this review is to highlight the recent advances in synthetic protocols and the new supramolecular strategies developed towards ratiometric $\mathrm{pH}$ imaging in living systems. In the first section, we review the advances in the synthetic routes towards the most important molecular cores of fluorescent dyes with special focus in near infrared (NIR) and $\mathrm{pH}$ ratiometric probes. In the second part of the review, we examine the newest applications of some of these molecules coupled to stimuli responsive supramolecular 
assemblies, which tackle specific sensing challenges with impressive accuracy in the complex biological media.

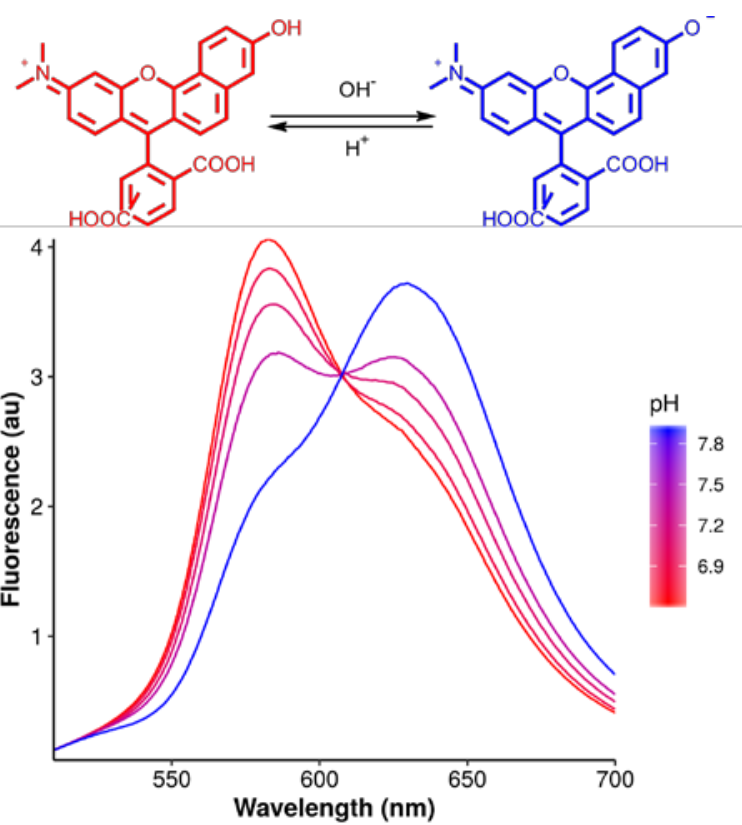

Figure 1. Spectra changes in the fluorescence emission of ratiometric probe SNARF-1 as function of the $\mathrm{pH}$. In an acidic environment $(\mathrm{pH}<\mathrm{pK}$ ) the maximum emission is observed at $580 \mathrm{~nm}$. In more alkaline media $\left(\mathrm{pH}>\mathrm{pK}_{\mathrm{a}}\right)$ the maximum emission at $580 \mathrm{~nm}$ decreases, while a second band at $630 \mathrm{~nm}$ emerges. The ratio between these two signals, $I_{630} / l_{580}$ provides an accurate way to measure intracellular $\mathrm{pH}$

Table 1. Usual commercial $\mathrm{pH}$ probes used for studying intracellular $\mathrm{pH}$ variations. With the exception of CyHer5T, all these probes are ratiometric either in absorption or emission. ${ }^{[8]}$

\begin{tabular}{ccccc}
\hline Family & Name & $\lambda_{\text {em,max }}(\mathrm{nm})$ & pKa & Ref \\
\hline Xanthenes & BCECF & 530 & 7 & 9 \\
Xanthenes & Fluorescein (63) & 520 & $6.4 / 5$ & 9 \\
Xanthenes & Oregon Green & 514 & 4.8 & 7 \\
Xanthenes & SNARF-4F (77) & $595 / 665$ & 6.4 & 10 \\
8-Hydroxypyrene & HPTS (4) & 514 & 7.3 & 7 \\
Pyridyl oxazole & $\begin{array}{c}\text { Lysosensor DND- } \\
\text { 160 }\end{array}$ & $450 / 510$ & 4.2 & 9 \\
Cyanines & CypHer5T & 660 & 6.1 & 8 \\
\hline
\end{tabular}

\section{Synthetic approaches for $\mathrm{pH}$ ratiometric} probes

Several $\mathrm{pH}$ sensitive molecular probes have been reported and some of them are commercially available (Table 1$).^{\left[{ }^{[9]}\right.}$ Traditional fluorescent molecular cores include xanthene $(1),{ }^{[10,11]}$ boron dipyrromethene fluoride (BODIPY, 2) ${ }^{[12]}$ and cyanine (3) ${ }^{[13]}$ and other molecular scaffolds such as pyrene (4) and 4-Nitro-2,1,3benzoxadiazole (NBD, 6), ${ }^{[14]}$ and 1,8-naphthalimide (NDI, 5) ${ }^{[15]}$ cores (Fig. 2).
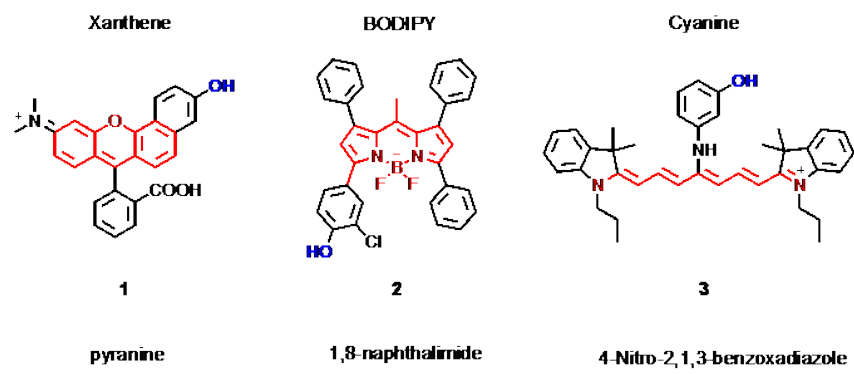

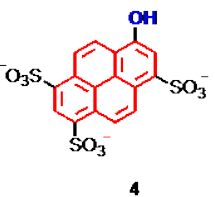<smiles>CCCNC(=O)NNc1ccc2c3c(cccc13)C(=O)N(CCC)C2=O</smiles><smiles>O=C1C=CC(NCN2CCOCC2)C2NON=C12</smiles>

6

Figure 2. Chemical structures of common molecular cores found in organic $\mathrm{pH}$-sensitive fluorescence probes. Red color denotes the structural core used The functional moieties responsible for $\mathrm{pH}$ sensing are in blue.

\subsection{Cyanine Core}

Cyanine is the non-systematic name of a family of polymethines dyes that can be classified in: streptocyanines or open chain cyanines (7), hemicyanines (8) and closed chain cyanines (9) in where the two nitrogen atoms are connected by the polymethine chain (Fig. 3A). The nitrogen atoms can be part of a heteroaromatic core such as pyrrole, imidazole, thiazole, pyridine, quinoline, indole, benzothiazole, etc. The high number of delocalized $\pi$-conjugated electrons turns the cyanine core into one of the best scaffolds to develop NIR fluorescent probes. Additionally, cyanine dyes are biocompatible, show low cytotoxicity in living cells and have been widely applied in the sensing of metal ions, $\mathrm{pH}$, anions, reactive small molecules, biomacromolecules and environment related factors such as temperature, polarity and viscosity. ${ }^{[16-18]}$ 

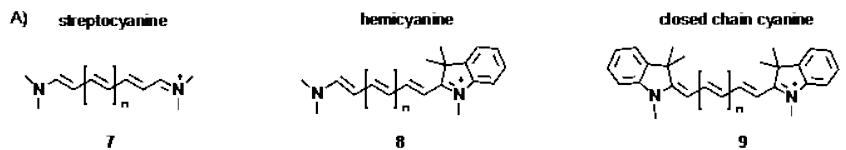

B)

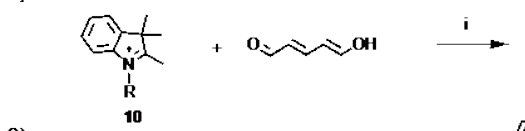

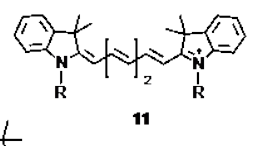

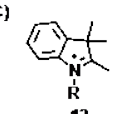
co<smiles>[N-]=[N+]=CC=CC=CC=[NH2+]</smiles>

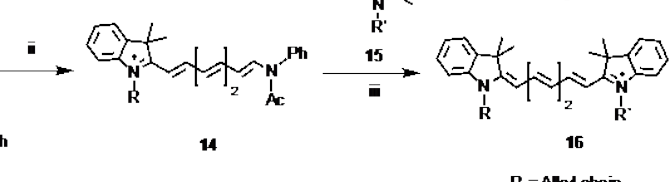

Figure 3. A) Three main types of cyanine dyes. B) Synthesis of symmetric cyanines. C) Synthesis of asymmetric cyanines. Reaction conditions: i) $\mathrm{NaOAc} / \mathrm{EtOH}$; ii) Ac2O, $150^{\circ} \mathrm{C}$; iii) $\mathrm{NaOAc} / \mathrm{EtOH}$

A number of synthetic procedures towards the polymethine skeleton of cyanines have been described in the literature. ${ }^{[19]}$ The general synthetic approach consists in the condensation of an indolinium with the corresponding unsaturated electrophiles (Fig. 3B). ${ }^{[19]}$ Double condensation of the same indolinium partner (10) leads to symmetrical cyanines (11) (Fig. 3B), while a stepwise reaction can be employed to access asymmetrical cyanines (16) (Fig. 3C). This strategy have also allowed the preparation of a large number of styryl pyridinium dyes. ${ }^{[20]}$ Other methods involve the condensation of 4-methylquinolinium or 4methylpyridinium salts with 2-methylthioheterocyclic salts ${ }^{[21]}$ or the condensation between cationic heterocycles with phenyl imino derivatives of malondialdehyde. ${ }^{[22]}$ Cyanine dyes have also been prepared with complex heterocycles, ${ }^{[23]}$ fluorinated polymethine chains, ${ }^{[24]}$ and equipped with $\mathrm{pH}$ detection capabilities. ${ }^{[25]} \mathrm{pH}$ triggered fluorescent cyanines have been intensively studied, in particular, cyanine derivatives with non- $N$ alkylated indolium structures (i.e. 17-21, Fig. 4). ${ }^{[8,25-27]}$ These probes are quenched when the nitrogen atom is not protonated, but become highly fluorescent after protonation in acidic environments.

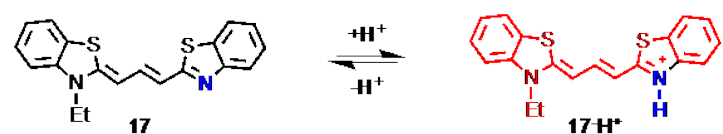

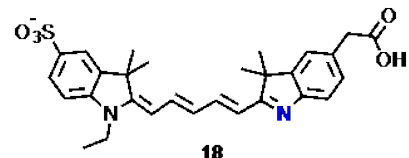

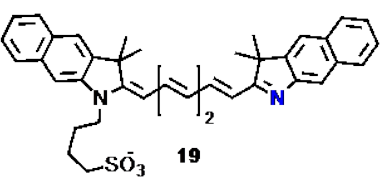

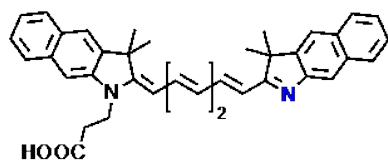<smiles>COC(=O)CN1/C(=C/C=C(Cl)/C=C/C2=Nc3ccc(S(=O)(=O)[O-])cc3C2(C)C)C(C)(C)c2cc(S(=O)(=O)[O-])ccc21</smiles>

21

Figure 4. Cyanines as $\mathrm{pH}$-triggered fluorescent probes. The acidic nitrogen is shown in blue. The protonated emitting fluorophore is shown in red.

Ratiometric $\mathrm{pH}$ sensitivity in cyanine probes, with $\mathrm{N}$-alkylated indolium structures (22 and 23), was achieved by incorporation of a proton sensitive phenol (22) or terpyridine moiety (23) at the conjugated chain double bond (Fig. 5). ${ }^{[28,29]}$ The pKa of these type of ratiometric cyanine probes was optimized by piperazine insertion in 24 (Fig. 5). ${ }^{[30]}$ Under acidic conditions these $\mathrm{pH}$ probes showed a $46-83 \mathrm{~nm}$ red shift in the absorption maximum, which is reversible and large enough to allow ratiometric $\mathrm{pH}$ sensing (Fig. 5) Hemicyanines $\mathbf{2 5}$ and $\mathbf{2 6}$ have been reported as $\mathrm{pH}$ probes as well (Fig. 5). ${ }^{[31,32]}$ The zwitterionic hemicyanine probe $\mathbf{2 5}$ was designed with multiple reactive sites towards $\mathrm{OH}^{-} / \mathrm{H}^{+}$together with aggregation-induced emission capability from a tetraphenylethene moiety, which enable a broad range of $\mathrm{pH}$ detection. ${ }^{[31]}$ Through-bond energy transfer (TBET) has been explored in $\mathrm{pH}$-ratiometric probes such as $\mathbf{2 7}$ including a tetraphenylethene (TPE) donor and near-infrared hemicyanine acceptor (Fig. 5). Hemicyanine 27, 29 showed a large pseudoStokes shift and well-defined dual emissions, which allowed simultaneous imaging readouts with the visible and near-infrared fluorescence channels. Interesting sulfonated alternatives with modulated $\pi$-conjugated systems were obtained by connecting the TPE and the hemicyanine moieties by single or double bonds (28 in Fig. 5). ${ }^{[33]}$ 


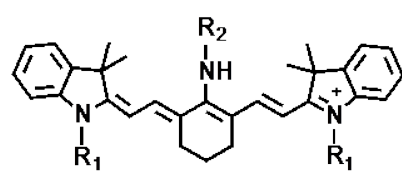

$$
22 \mathrm{R}_{1}=\mathrm{Pr}, \mathrm{R}_{2}=
$$$$
23 R_{1}=P r, R_{2}=\ldots
$$$$
24 R_{1}=M e ; R_{2}=\left[\begin{array}{l}
N \\
N
\end{array}\right]
$$

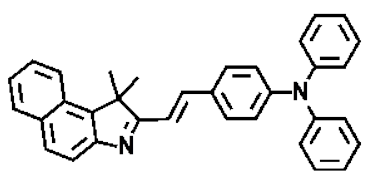

26

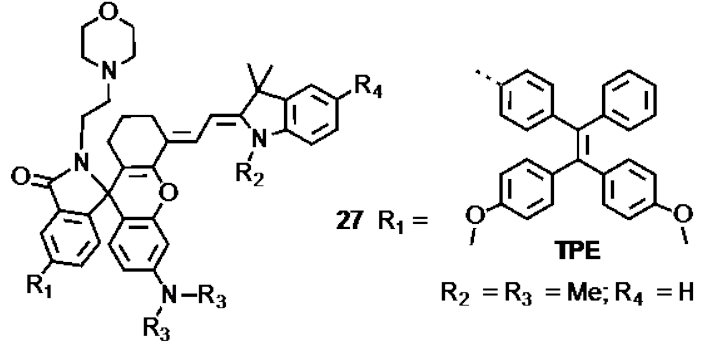

$28 \mathrm{R}_{\mathbf{1}}=\mathrm{H} ; \mathrm{R}_{2}=\left(\mathrm{CH}_{23}\right)_{3} \mathrm{SO}_{3}^{-} ; \mathrm{R}_{\mathbf{3}}=\mathrm{Et}, \mathrm{R}_{\mathbf{4}}=\mathrm{TPE}$

$29 R_{1}=H ; R_{2}=M e ; R_{3}=E t ; R_{4}=$<smiles>CC=Cc1ccc(C(=C(c2ccccc2)c2ccc(OC)cc2)c2ccc(OC)cc2)cc1</smiles>

Figure 5. Example of cyanines as ratiometric $\mathrm{pH}$ fluorescence probes

In hemicyanine derivatives $\mathbf{3 0 - 3 3}$, the ratiometric $\mathrm{pH}$ sensitivity is based on the protonation/deprotonation of a hydroxyl group inserted in a xanthene counterpart. In this structure, the pKa modulation could be achieved by modification of the xanthene with electron-withdrawing groups such as benzothiazole (30) (Fig. 6A) ${ }^{[34]}$ Following on this concept, a similar strategy with a fluorine atom in the chromenylium-cyanine fluorophore $\mathbf{3 4}$ showed a low pKa value of 6.3 allowing lysosomal tracking (Fig. $6 B) \cdot{ }^{[35]}$

Ratiometric two-photon (TP) fluorescent probes, $\mathrm{PSIOH}$ (35) and PSIBOH (36), were obtained by a carbazole-oxazolidine $\pi$ conjugated system, which allows an effective $\mathrm{pH}$ sensing in biological systems (Fig. 7). Remarkably, PSIOH (35) exhibited an fluorescence emission shift of $169 \mathrm{~nm}$ upon protonation with a pKa value of 6.6 and a linear variation range between $\mathrm{pH} 6$ and $7 .^{[36]}$

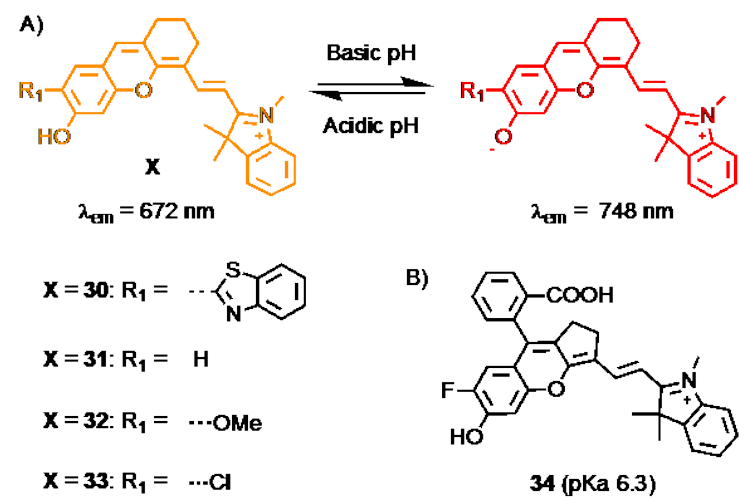

Figure 6. A) Hemicyanine derivatives $\mathbf{3 0 - 3 3}$ and ratiometric emission. B) Hemicyanine $\mathbf{3 4}$ with optimized pKa. 


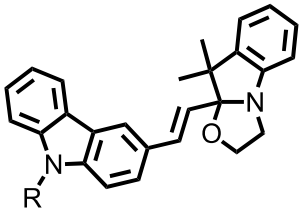

$\mathrm{PSIOH}(35)$

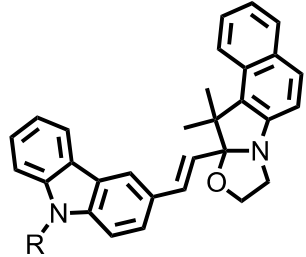

PSIBOH (36)

$$
\mathrm{R}=\cdot \sim \mathrm{O}^{\mathrm{O}}
$$

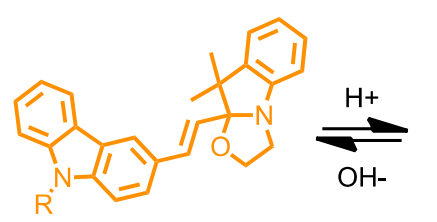

$\mathrm{I}_{\mathrm{em}}=435 \mathrm{~nm}$<smiles></smiles>

$\mathrm{I}_{\mathrm{em}}=604 \mathrm{~nm}$
Figure 7. Molecular structures of $\mathrm{PSIOH}(35)$ and $\mathrm{PSIBOH}(36)$ and $\mathrm{pH}$ sensing response of $\mathrm{PSIOH}$.

In the ratiometric $\mathrm{pH}$-sensitive fluorophores $\mathbf{3 7}$ and $\mathbf{3 8}$, (Fig. 8) the modulation of the $\pi$-conjugation of the probe was exploited by linking a coumarin dye with a near-infrared hemicyanine moiety by a double bond connector (Fig. 8). ${ }^{[37]}$ The hemicyanine was completed with a xanthene moiety and a lysosometargeting morpholine ligand in $\mathbf{3 7}$ or a phenylamine group in $\mathbf{3 8}$. At neutral $\mathrm{pH}$, only the coumarin emission is observed, as the fluorescence of the hemycianine is quenched by formation of the closed spirolactam structures. However, decrease of $\mathrm{pH}$ triggers spirolactam ring opening and significantly enhances the $\pi$ conjugation of the probes producing new near-infrared fluorescence peaks of the hemicyanine at $755 \mathrm{~nm}$ and $740 \mathrm{~nm}$ for probes $\mathbf{3 7}$ and $\mathbf{3 8}$ respectively (Fig. 8). Moreover, these probes displayed ratiometric fluorescence response with the coumarin emission decreasing and the hemicyanine emission as the $\mathrm{pH}$ changes from 7.4 to 2.5 .

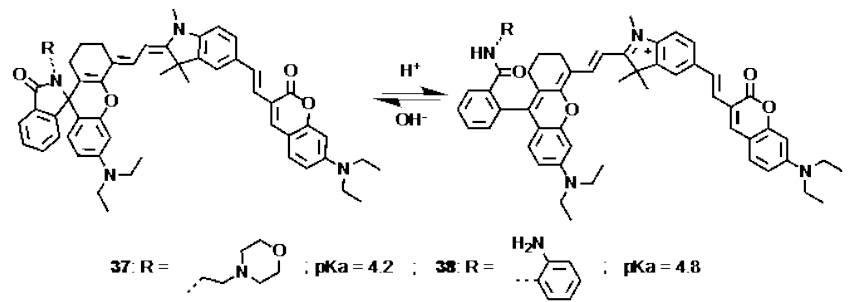

Figure 8. Chemical structure response of fluorescent probes $\mathbf{3 7}$ and $\mathbf{3 8}$ to $\mathrm{pH}$ changes with $\pi$-conjugation modulation.

The excited-state intramolecular proton transfer (ESIPT) was exploited by coupling two molecular segments benzothiazolium and the derived cyanine (Fig. 9). The resulting NIR-emitting probe $39(\square$ em $\sim 700 \mathrm{~nm})$ showed a large Stokes shift $(234 \mathrm{~nm})$ and a strong fluorescence at acidic $\mathrm{pH}$. The probe diffuses into lysosome organelles and its NIR-fluorescence is strongly enhanced after reversible acid-triggered phenol/phenoxide interconversion (ESIPT) together with intramolecular charge transfer (ICT) (Fig. 9). ${ }^{[38]}$

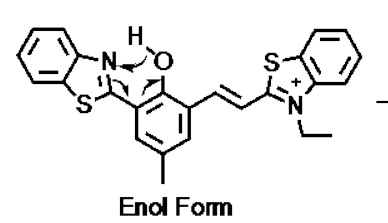

39
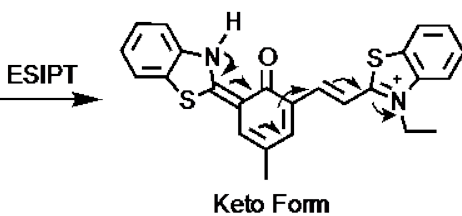

Keto Form

39

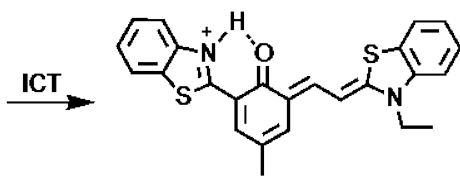

Basic Form

39

Figure 9. Structures of enol and keto tautomers, ESIPT and ITC. 


\subsection{Bodipy Dyes}

The boron-dipyrromethene, BODIPY, probes are a class of fluorescent dyes constituted by a dipyrromethene that chelates a disubstituted boron atom, typically a $\mathrm{BF}_{2}$ unit. BODIPY dyes are relatively easy to synthesize in high yield and multi-gram quantity and their excellent spectroscopic/photophysical properties can be easily tuned by introducing different electron releasing/withdrawing groups into the BODIPY core. ${ }^{[12]}$
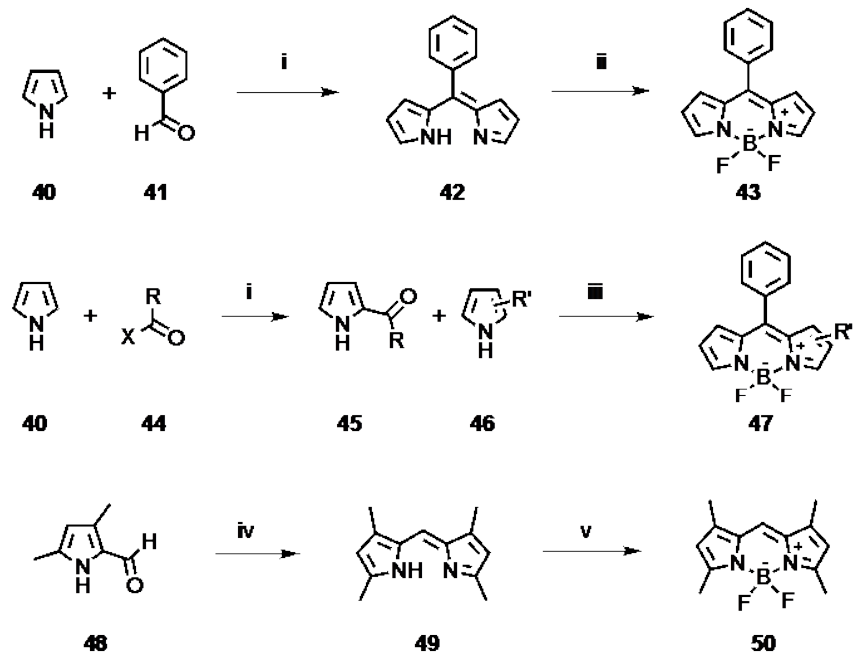

Figure 10. Synthetic approaches for the preparation of BODIPY probes. R' defines any alkyl or aryl substituent. $X$ denotes activated carboxylic acids, acid anhydrides or orthoesters. Reaction conditions: i) 1.TFA, $25{ }^{\circ} \mathrm{C}, 45-80 \%$; ii) $\mathrm{DDQ}$, then $\mathrm{Et}_{3} \mathrm{~N}, \mathrm{BF}_{3}$-etherate. $22 \%$ overall; ${ }^{[42]}$ iii) $\mathrm{X}=\mathrm{Cl}, 91-77 \%$; iv) $\mathrm{BF}_{3-}$ etherate, $\mathrm{R}_{3} \mathrm{~N}, 66-34 \% ;{ }^{[43]}$ v) $\mathrm{POCl}_{3}, \mathrm{DCM}, 25^{\circ} \mathrm{C}, 12 \mathrm{~h}$; vi) $\mathrm{BF}_{3}$-etherate, $\mathrm{Et}_{3} \mathrm{~N}$, $\mathrm{DCM}, 25^{\circ} \mathrm{C}, 12 \mathrm{~h} .92 \%$ overall yield $\mathrm{v}$ and vii. ${ }^{[41]}$

The simple synthetic approach towards the BODIPY core is mainly based in porphyrin chemistry involving the acid-catalyzed condensation of pyrrole derivatives (40) with aldehydes (41) (Fig 10). ${ }^{[12]}$ Oxidation of the resulting dipyrromethane in mild conditions (i.e. DDQ) affords the dipyrromethene (42) that is complexed with boron trifluoride in basic media to give rise to the borondifluoride complex (43). Alternatively, asymmetric BODIPY dyes (47) can be prepared by sequential condensation of pyrrole derivatives (40) with activated carboxylic acids (i.e. 44) or acid anhydrides ${ }^{[39]}$ or orthoesters. ${ }^{[40]}$ The isolation of the corresponding acylpyrrole (45) allows the access to asymmetric dipyrrins, which again, can be treated with an excess of base and boron trifluoride etherate to yield the final BODIPY (47). A third strategy involves the self-condensation of acetylated pyrrole-2-carbaldehyde (48) promoted by phosphorus oxychloride to obtain dipyrromethene (49) that can be further functionalized to give rise to the BODIPY (50) in high yields after simple chromatographic purification (Fig. 10). ${ }^{[41]}$ BODIPY are hydrophobic and robust probes that allow many post-synthetic modifications on the meso-aryl substituent, such as oxidation, reduction and nucleophilic aromatic substitution, without significant decomposition of the dye. ${ }^{[12]}$

The BODIPY scaffold has been widely exploited in $\mathrm{pH}$ fluorescent probes ${ }^{[44]}$ and in numerous examples for other analytes. ${ }^{[11,40]}$ BODIPY derivatives bearing hydroxyl groups (5153), have been reported as fluorescent probes for $\mathrm{pH}$ sensing in aqueous and mixed aqueous-organic media (Fig. 11). ${ }^{[45}$ However, not all of these molecules are suitable for intracellular $\mathrm{pH}$ measurements. In probes 54-57, aqueous solubility was achieved by insertion of two carboxylate pendants and the presence of an aniline pendant quenched the fluorescence of the probe at neutral $\mathrm{pH}$ by photoinduced electron transfer (PET) and became highly fluorescent after protonation of the nitrogen atom (Fig. 11). ${ }^{[46]}$ These probes can potentially be used as a clinical tool for cancer detection and real-time monitoring of anticancer therapeutic effects. This concept has been recently extended for intriguing lysosome-targeted $\mathrm{pH}$-ratiometric probes with NIR emission, which incorporated p-dimethylaminostyryl moieties to extend the conjugation of the BODIPY core. ${ }^{[47]}$

The $\mathrm{pH}$-activatable BODIPY $\mathbf{5 8}$ was prepared by a modified Knoevenagel condensation followed by pegylation of the phenyl vinyl tails by an azide-alkyne click cycloaddition (Fig. 11). Although no ratiometric behaviour was reported, aniline modification allowed pKa tuning and the probes showed high quantum yield and optimal orbital energies to enable $\mathrm{pH}$ controlled photoinduced electron transfer $(\mathrm{PeT})$. This near infrared emissive probe was designed with improved water solubility and circulating times in living systems, which allowed high in vivo tumour detection and minimal liver activation. ${ }^{[48]}$

The off/on fluorescence switching in the NIR BODIPY 59 is controlled by a reversible phenol/phenolate interconversion. The deprotonated phenolate species dominates at physiological $\mathrm{pH}$ 7.2 and results in intramolecular charge transfer quenching of the probe. The good selectivity of $\mathbf{5 9}$ towards lysosomes was confirmed by experiments in a HeLa cells that expressed the lysosomal-associated membrane protein 1 fused to green fluorescent protein. ${ }^{[49]}$ In the NIR pH sensitive ratiometric probes 60a-e, substitution of the tertiary anilines or the phenol subunits allowed pKa tuning and the introduction of a sulfobetaine moiety, in the BODIPYs core, improved the water solubility and minimized nonemissive aggregation. ${ }^{[50]}$ 


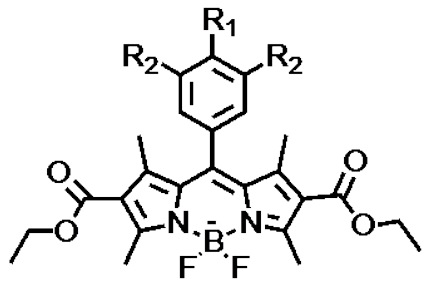

$51 R_{1}=O H, R_{2}=H$
$52 R_{1}=O H, R_{2}={ }^{t} B u$
$53 R_{1}=R_{2}=H$

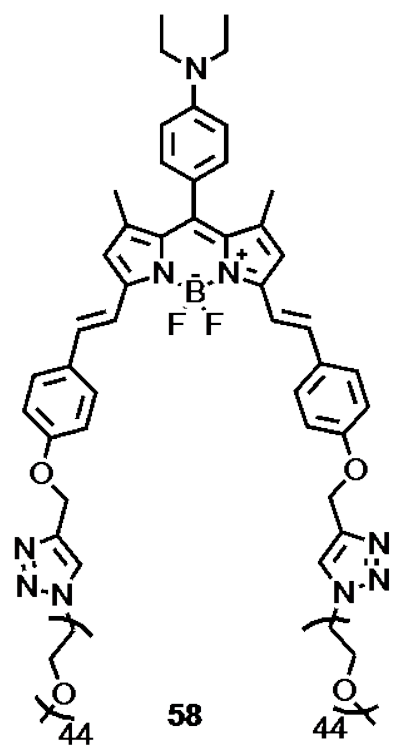

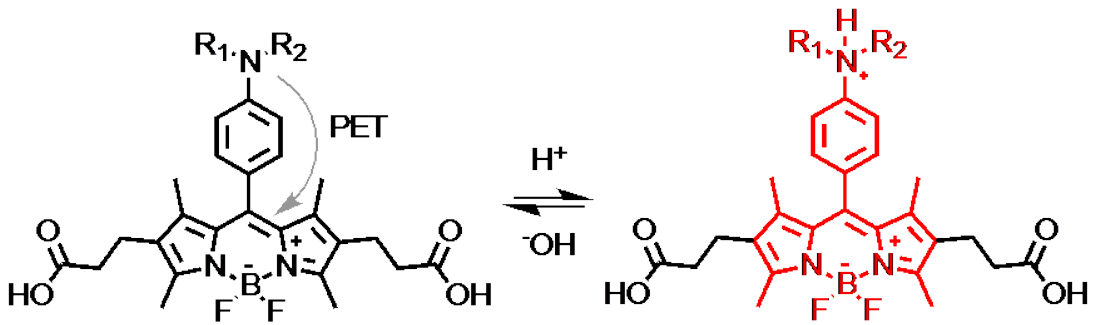

$54 R_{1}=R_{2}=H$

$55 R_{1}=R_{2}=M e$

$56 \mathrm{R}_{1}=\mathrm{Me}, \mathrm{R}_{2}=\mathrm{Et}$

$57 R_{1}=R_{2}=E t$

Figure 11. Examples of BODIPYs as pH fluorescent probes.

\subsection{Xanthene dyes}

The xanthene family include well-known probes such as fluorescein, eosins, rhodamines, etc. Xanthenes have excellent photophysical properties such as high extinction coefficients, quantum yields, photostability and relatively long emission wavelengths. Fluorescein (63), one of the most widely used xanthenes probes, can be synthesized by two consecutive acidcatalysed Friedel Craft's reactions between phthalic anhydride (61) and resorcinol (62a) (Fig. 12). The fluorinated fluorescein analogue (Oregon Green) was prepared by the reaction of fluororesorcinols with phthalic anhydride and its derivatives (Fig. 12). ${ }^{[51]}$ However, the xanthene core is robust enough to allow post-synthetic modifications in several activated positions. For example, fluorescein is capable of undergo different direct electrophilic aromatic substitutions (SEAr) such as halogenation, ${ }^{[52]}$ or sulfone insertion. ${ }^{[53]}$

Rhodamines and related analogues (i.e. 63-68) can be prepared by the acid-catalyzed condensation of aminophenols with phthalic anhydrides (Fig. 12A). ${ }^{[54]}$ Rhodamines and Rhodols can also be synthesized from 3',6'-dibromofluoresceins (64) by $\mathrm{Pd}$ catalyzed Buchwald-Hartwig amination reactions (Fig. 12A). ${ }^{[55]}$ This synthesis can be performed stepwise, thus providing control over the symmetry of the xanthene core as in $\mathbf{7 2}$ (Fig. 12B). ${ }^{[56]}$ This two-step route has been use to synthesized xanthene $\mathrm{pH}$ sensitive probes such as SNARF (3). 
A)<smiles>O=C1OC(=O)c2ccccc21</smiles>

61<smiles>[R]c1cccc([R])c1</smiles>

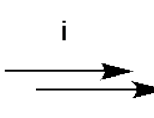

$62(a, b, c)$

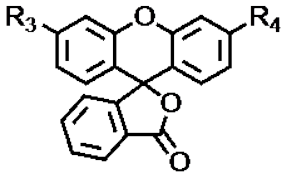

63, $\mathrm{R}_{3}, \mathrm{R}_{4}=\mathrm{OH}$

64, $\mathrm{R}_{3}, \mathrm{R}_{4}=\mathrm{Br}$

65, $R_{3}, R_{4}=N R_{2}$

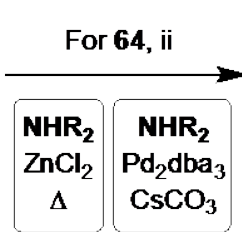

a, $\mathrm{R}_{1}, \mathrm{R}_{2}=\mathrm{OH}$

b, $\mathrm{R}_{1}=\mathrm{OH}, \mathrm{R}_{2}=\mathrm{Br}$

c $\mathrm{R}_{1}=\mathrm{NH}_{2}$ or $\mathrm{NR}_{2}, \mathrm{R}_{2}=\mathrm{OH}$<smiles>[R]CSc1ccc2c(c1)Oc1cc(N[R3])ccc1C21OC(=O)c2ccccc21</smiles>

66, $\quad \mathrm{R}_{5}=\mathrm{Ph}$

67, $\mathrm{R}_{5}=\mathrm{Q}^{\mathrm{N}}$.

68, $\quad R_{5}=E$.

B)

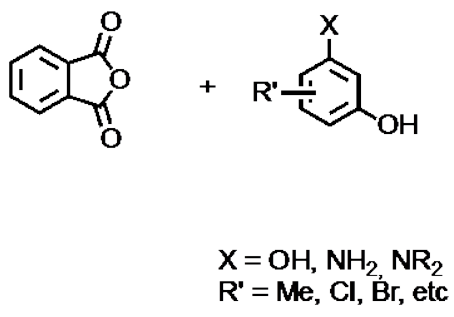

61
69<smiles>[X]c1cc(O)c(C(=O)c2ccccc2C(=O)O)cc1[R]</smiles>

$\mathrm{R}^{\prime \prime}=\mathrm{Me}, \mathrm{Cl}, \mathrm{Br}$, etc

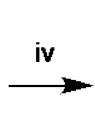

$\mathrm{X}=\mathrm{OH}, \mathrm{NH}_{2} \mathrm{NR}_{2}$ $\mathrm{R}^{\prime}$ and $\mathrm{R}^{\prime \prime}=\mathrm{Me}, \mathrm{Cl}, \mathrm{Br}$, etc.

72, $X=O H, R^{\prime}=H, R^{\prime \prime}=H$

Figure 12. Strategies for the synthesis of xanthene fluorescence probes. A) Rhodamines and Rhodols based probes. B) General synthetic scheme probes. Reaction conditions: i) $\mathrm{MeSO}_{3} \mathrm{H}$, heating. e.g. for $\mathrm{R}_{1}=\mathrm{R}_{2}=\mathrm{R}_{3}=\mathrm{R}_{4},=\mathrm{OH}$ or $\mathrm{Br}, 100-90{ }^{\circ} \mathrm{C}, 85-43 \%$; ;57] ii) $\mathrm{NHR}_{5} \mathrm{R}_{6} \mathrm{ZnCl}_{2}$, heating, or $\mathrm{R}_{3}, \mathrm{R}_{4}=\mathrm{TfO}$, then $\mathrm{NHR} \mathrm{R}_{6}, \mathrm{Pd}_{-}$ ligand, $\mathrm{Cs}_{2} \mathrm{CO}_{3}$, solvent, $100^{\circ} \mathrm{C}, 96-35 \%$; ${ }^{[58]}$ iii) heating, e.g. for $\mathrm{X}=\mathrm{Me}_{2} \mathrm{~N}$, reflux in toluene, $53 \%$; ${ }^{[59]}$ iv) $\mathrm{H}^{+}$.

Xanthene-based $\mathrm{pH}$ probes include fluorescein (63), seminaphthorhodafluor (SNARF), and rhodamine derivatives. ${ }^{[60]}$ Fluorescein, one of the first $\mathrm{pH}$ probes employed in biology, presents several limitations related to photobleaching, emission quenching at acid $\mathrm{pH}$, leakage from cells, high pKa values, etc. The introduction of electron-withdrawing groups (e.g., $\mathrm{Cl}$ atom) into fluorescein core lowers their pKa values ${ }^{[61]}$ and the resulting chlorinated fluoresceins (e.g. 73, 74) could be suited for low $\mathrm{pH}$ detection in cells. ${ }^{[62]}$ Nevertheless, seminaphthorhodafluor (SNARF) derivatives $(\mathbf{3}, \mathbf{7 5 - 7 6})$ are preferred for ratiometric $\mathrm{pH}$ sensing due to their excellent quantum yields and red-shifted dual-emission wavelengths $(\square$ em $\sim 500-600 \mathrm{~nm}){ }^{[61,63]}$ In these probes the deprotonation of the phenol controls the ratiometric emission of the basic and acid forms of the probe. Again, the introduction of electron withdrawing groups lowers the pKa of these ratiometric probes. The perfluorination of the phenyl ring attached to the xanthene core in 76 gave a pKa of $\sim 7.4$, which was suitable for intracellular $\mathrm{pH}$ sensing. For more acidic compartments SNARF-4F (77) and SNARF-5F (78) showed pKa values of 6.4 and 7.2 respectively. ${ }^{[10]}$
In $\mathrm{pH}$ sensitive rhodamines the spirolactam/open-ring isomerism controls the pH sensitivity of the probes (Fig. 13) ${ }^{[64]}$ For example, in neutral physiological conditions, the probes $\mathbf{7 9}$ and $\mathbf{8 0}$ exist in a nonfluorescent spirocyclic form (Fig. 13). However, acidification leads to the spirolactam ring-opening, resulting the emission of fluorescence. These probes, with $\mathrm{pKa}$ values between 4-6, could be used for imaging of acidic organelles such as endosomes and lysosomes. These rhodamines probes have also been employed to detect the increase of the chloroquine and the $\mathrm{pH}$ changes in lysosomes during apoptosis in live cells. ${ }^{[65]}$ The on hydronium-ion-mediated reversible dehydroxylation of 9-Aryl-9H-xanthen-9-ol has been reported as an efficient fluorimetric and colorimetric $\mathrm{pH}$ indicator. ${ }^{[66]} \mathrm{pH}$ sensitive piperazines switches, operating by photoinduced electron transfer, have allowed the imaging of vesicular dynamics in living cells with good intra-vesicular acidic activation, high staining specificity and good photostability. ${ }^{[67]}$ 
<smiles>O=C(O)c1c(Cl)cccc1-c1c2ccc(=O)cc-2oc2cc(O)ccc12</smiles>

73<smiles></smiles>
79, $\mathrm{R}_{1}=\mathrm{Et}, \mathrm{R}_{2}=\ldots \mathrm{NH}_{2}$<smiles>O=C(O)c1c(Cl)c(Cl)c(Cl)c(Cl)c1-c1c2cc(Cl)c(=O)cc-2oc2cc(O)c(Cl)cc12</smiles>

74<smiles>[R]c1c([R])c([R])c(-c2c3ccc(=[N+](C)C)cc-3oc3c2ccc2cc(O)ccc23)c(C(=O)O)c1[R]</smiles>

$3 \mathrm{R}=\mathrm{H}$
$75 \mathrm{R}=\mathrm{Cl}$

$76 \mathrm{R}=\mathrm{F}$<smiles></smiles>

$\pi, R_{1}=F, R_{2}=H$

$\mathbf{7 8}, \mathrm{R}_{\mathbf{1}}=\mathrm{H}, \mathrm{R}_{\mathbf{2}}=\mathrm{F}$<smiles>Cc1cc(C(=O)[O-])cc(C)c1C1=c2cc3c(cc2[Si](C)(C)c2cc(N4CCN(Cc5ccc(S(=O)(=O)[O-])cc5[S-](=O)([O-])[O-])CC4)ccc21)=[N+](C)CCC3</smiles>

$\mathrm{SiRpH}_{5}(\mathbf{8 1})$<smiles>[R]NC(=O)c1ccccc1-c1c2cc(C)c(=[NH+][R])cc-2oc2cc(N[R])c(C)cc12</smiles>

$\mathrm{R}_{2}=$.. $\stackrel{+}{\mathrm{NH}_{3}}$

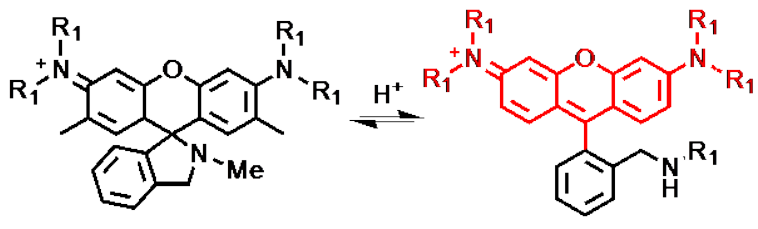

80, $R_{1}=E t$

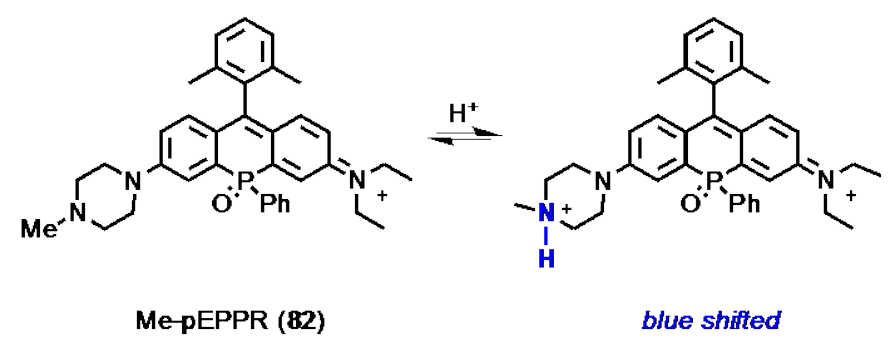

Figure 13. Example of Xanthenes as $\mathrm{pH}$ fluorescence probes.

Recently, it has been reported that the substitution of the oxygen atom of the xanthene probes by a silicon or phosphorous atom, strongly shifted to the red the fluorescence emission of these ratiometric probes. ${ }^{[68]}$ These scaffolds can also be synthetically modified to modulate the pKa value and the absorption and emission wavelengths. Attachment of protonotable piperazine moieties to the xanthene core allowed an absorption shift of about $80 \mathrm{~nm}$ to shorter wavelength in acidic aqueous solutions. In particular, two fluorescence probes based on these scaffolds (SiRpH5 81 and Me-pEPPR 82) have showed excellent potential for imaging the $\mathrm{pH}$ inside cells and in tumor tissue. ${ }^{[68]}$ The rhodamine/coumarin CM-ROX dual probe, was designed with a coumarin moiety with "always-on" blue fluorescence and a "acidactivatable" rhodamine-lactam counterpart. This dual colour probe allowed $\mathrm{pH}$ ratiometric sensitivity in cells undergoing autophagy, cell death, and viral infection. ${ }^{[69]}$

\subsection{Other molecular scaffolds}

Particular examples of different molecular cores have been recently synthesized with $\mathrm{pH}$ sensitivity or with potential application in $\mathrm{pH}$ sensitive molecular devices: pyrene derivatives, 4-Nitro-2,1,3-benzoxadiazole (NBD) and 1,8-naphthalimide (NDI) cores (Fig. 14A). A pyrene-based colorimetric and fluorescent $\mathrm{pH}$ probe 2-pyrenyl-1,8-naphthyridine (PNY) (83) displayed excellent $\mathrm{pH}$-dependent optical properties and a linear response in the $\mathrm{pH}$ range of 2.4-3.7. PNY showed a large Stokes shift $(145 \mathrm{~nm})$, which can effectively reduce potential excitation interference. Moreover, PNY exhibited excellent photostability and high selectivity among different metal cations and amino acids. This probe was used to monitor $\mathrm{pH}$ fluctuations in A549 cells and imaging extreme acidity in Escherichia coli cells. ${ }^{[14]}$ NBD-based probes have also been reported to monitor intracellular $\mathrm{pH}$ and label lysosomal compartments. ${ }^{[70]}$ Dual ratiometric fluorescent probes for $\mathrm{pH}$ and temperatures based on single thermoresponsive polymer chains, 
NBD-P(OEGMA-Co-DEGMA)-RhB2 have been described (84). These probes were site-specifically labeled with a FRET donor (NBD) and a RhB-ethylenediamine derivative possessing off-on $\mathrm{pH}$-switchable emission characteristics. ${ }^{[70]}$ Very recently a new series of NBD derivatives fluorophores (SCOTfluors) (85-89) have been synthesized (Fig. 14B). ${ }^{[71]}$ SCOTfluors are smallsized fluorophores covering the entire visible spectrum. These probes are readily obtained by bridging aminoanilines with different groups and include the smallest NIR-emitting fluorophores to date. SCOTfluors are not $\mathrm{pH}$ sensitive but new derivatives based of these structures will have an impressive potential to be used in $\mathrm{pH}$ sensitive molecular devices.

1,8-Naphthalimide (NDI) fluorescence probes show good in vitro spectroscopic response to $\mathrm{pH}$ variations. Based on this core, a turn-on sensitive fluorescent probe, NT1 (90), was developed for lysosomal $\mathrm{pH}$ tracking during heat stroke. ${ }^{[72]}$ Other example is DPFP (dual-function probe for imaging FA and $\mathrm{pH}$ ) (91) the first fluorescent probe with a homoallylamino group capable of detecting $\mathrm{pH}$ and formaldehyde. ${ }^{[73]}$ This probe has been successfully used in confocal fluorescence imaging of acidic lysosomes and exogenous or endogenous formaldehyde of HeLa cells.
A)

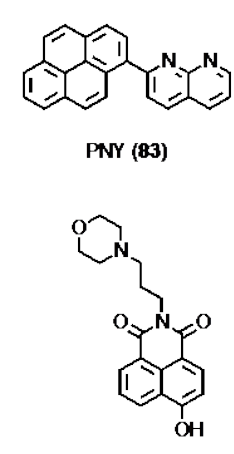

NT1 (90)

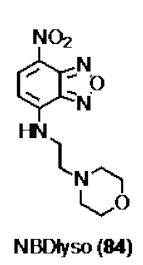

B)

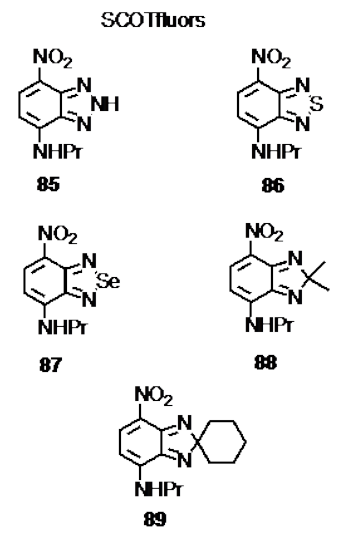

DPFP (91)

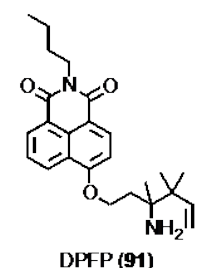

Figure 14. A) Pyrene-Based, NBD and NPI pH probes. B) SCOTfluors.

\section{Supramolecular approaches for $\mathrm{pH}$ sensing}

The previously discussed synthetic routes to the different fluorescent cores have made possible the preparation of a plethora of well-defined molecular probes that can be employed to report on $\mathrm{pH}$ changes within the cells. ${ }^{[74]}$ These fluorescent probes constitute essential tools for chemical and molecular biologist to follow and study different fundamental cellular processes. ${ }^{[75]}$ However, the complexity of the intracellular environment is prone to interfere with the precise imaging of cellular processes. For instance several fluorescent probes can suffer from lack of selectivity, low signal to noise ratio, photobleaching, quenching by aggregation, poor cell internalization, changes of spectroscopic properties due to interaction with membranes, proteins, cell organelles, etc. ${ }^{[6,76-80]}$ In vivo fluorescent tracking can be highly challenging due to the potential interactions of the delivered probes with internal endogenous biomolecules and proteins and can lead to the eventual non-desired accumulation of the probes within the organism. In this regard, proteins can be engineered to work as fluorescent biosensors ${ }^{[81]}$ offering the opportunity to target specific cell compartments. ${ }^{[82]}$ Although, fluorescent protein engineering and labelling has been of critical importance for the field, fluorescent proteins still suffer from important limitations such as limited scale production, problems with structural and chemical modifications as well as experimental technical limitations. Therefore, the combination of molecular fluorescent probes with artificial self-assembled systems constitutes an excellent alternative to tackle several complex challenges of current intracellular imaging.

Supramolecular chemistry navigates between these two worlds by programming synthetic or natural fluorescent molecular entities to dynamically form larger supramolecular structures that can display a different luminescent behaviour. The selfassembly process of these systems are normally accomplished by different -very often weak and multivalent- non-covalent interactions such as hydrogen bonding, cation- $\pi$, anion- $\pi$ and $\pi-$ $\pi$ interactions, Van der Waals forces, dipole-dipole interactions, etc. ${ }^{[83]}$ The final self-assembled system can be spontaneously triggered at the required imaging conditions and thus it is feasible to design intelligent multicomponent systems by combining suitable molecular building blocks. These building blocks would be coupled to optimize different functions of the supramolecular probe such as improving cell penetration, increasing stability, defining sharper $\mathrm{pH}$ thresholds or enhancing dynamic range (range between the minimum and maximum fluorescence signal). The generation of the luminescent signal is normally integrated in the supramolecular system by well-known molecular fluorescent probes. ${ }^{[84]}$ In these cases, $\mathrm{pH}$ changes are typically translated into differences in the excitation/emission intensity, although several other reading outputs such as nuclear magnetic resonance, ${ }^{[85]}$ or photoacoustics ${ }^{[86]}$ can also be integrated in the self-assembled system. In $\mathrm{pH}$ sensitive fluorescent emitting supramolecular systems two landscapes are possible depending on the involvement of the self-assembly process in the modulation of the output signal. In a first scenario, the assembly does not have a direct impact on the signal changes. In this case the role of self-assembly is structural, its objective is the fabrication of supramolecular structures that bring all the necessary elements together so the final ensemble 
is able to carry out the required function. The second situation implies that the assembly process is directly involved in the modulation of the output signal and thus self-assembly changes have a reporter role. In both cases, conventional (and most of the time commercially available) dyes have been used for the preparation of supramolecular probes for $\mathrm{pH}$ measurements (see Table 2). In this sense, integration of these probes into supramolecular systems can impart responsive properties that molecular dyes per se do not possess. For example, while rhodamine green is $\mathrm{pH}$ insensitive over a range of $\mathrm{pH}$ values, their incorporation into micellar systems result in $\mathrm{pH}$-sensitive probes due to dynamic changes of the chemical environment those rhodamine green experiences according the assembly state of the micelle.

Table 2. Common fluorophores and dyes employed in the preparation of supramolecular probes for pH sensing. When no available in the original report, values for $\lambda_{\mathrm{ex}}, \lambda_{\mathrm{em}, \max }$ and $\mathrm{pKa}$ were obtained from ThermoFisher or Sigma-Aldrich distributors.

\begin{tabular}{|c|c|c|c|c|c|c|}
\hline Fluorophore & $\lambda_{\mathrm{ex}}(\mathrm{nm})$ & $\lambda_{\mathrm{em}, \max }(\mathrm{nm})$ & $\mathrm{pKa}_{]}^{[\mathrm{a}}$ & Supramolecular structure & Role & Ref \\
\hline Bromothymol blue & - & - & 6.8 & nanogel & $\begin{array}{l}\text { Imparts } \mathrm{pH} \\
\text { responsiveness by } \\
\text { light absorption }\end{array}$ & 84 \\
\hline Coumarin 6 & 460 & 500 & PI & nanogel & Provides signal at $\lambda_{1}$ & 84 \\
\hline Nile red & 560 & $630(\mathrm{EtOH})$ & $\mathrm{PI}$ & nanogel & Provides signal at $\lambda_{2}$ & 84 \\
\hline SNARF-1 & $488-530$ & $580 / 640$ & 7.5 & Membrane insertion peptide & Ratiometric signal & 95 \\
\hline BCECF & 490 & 530 & 7 & micelle & $\mathrm{pH}$ sensitive dye & 99 \\
\hline Alexa 633 & 632 & 647 & $\mathrm{PI}$ & micelle & Reference dye & 99 \\
\hline Fluorescein & 490 & 520 & 6.4 & micelle & $\mathrm{pH}$ sensitive dye & 100 \\
\hline Oregon Green & 500 & 514 & 4.7 & micelle & $\mathrm{pH}$ - sensitive dye & 99,100 \\
\hline Rhodamine B & 550 & 630 & $\mathrm{PI}$ & micelle & Reference dye & 100 \\
\hline Cy7 & 730 & 790 & n.d. & Supramolecular aggregate & $\begin{array}{l}\text { pH-dependent signal } \\
\text { upon aggregation }\end{array}$ & 150 \\
\hline Rhodamine green & 495 & 520 & $\mathrm{PI}$ & micelle & $\begin{array}{l}\text { Reporter/quencher } \\
\text { according micelle } \\
\text { formation }\end{array}$ & 125 \\
\hline Alexa 488 & 496 & 519 & $\mathrm{PI}$ & DNA & FRET pair Alexa 488 & 117 \\
\hline Alexa 647 & 650 & 665 & $\mathrm{PI}$ & DNA & FRET pair & 117 \\
\hline Alexa 546 & 556 & 573 & $\mathrm{PI}$ & DNA & FRET pair Alexa 488 & 117 \\
\hline
\end{tabular}

[a] $\mathrm{PI}=\mathrm{pH}$ insensitive, .d. $=$ not determined

\subsection{Structural role of self-assembly}

Self-assembly of individual molecules into higher order supramolecular aggregates provides a way for combining small fluorophores with functional building blocks. The final integrated devices can be designed to carry out ratiometric measurements, to enhance fluorophore stability or to improve cell penetration.
This "toolbox" concept has also been thoroughly employed in the context of drug delivery. ${ }^{[87]}$ However, supramolecular chemistry can also be used to confine chromophores at controlled nanometric distances and prevent its free diffusion out of the supramolecular probe. This situation can, for instance, enable or inhibit cross-talk between donor-acceptor pairs by energy transfer processes, such as fluorescence resonance energy transfer (FRET) or electron exchange. ${ }^{[88]}$ By carefully selecting a suitable set of fluorophores, given that at least one of them is $\mathrm{pH}$ 
sensitive, and a suitable strategy for their inclusion into selfassembled systems, several interesting studies have demonstrated the potential of supramolecular ratiometric $\mathrm{pH}$ probes. In this regard, Peng et al[ ${ }^{[84]}$ have reported a polyurethane nanogel intended for ratiometric $\mathrm{pH}$ sensing at physiological ranges. Polyurethane can be chemically modified to include hydrophilic and hydrophobic pendants. This amphiphilic polymer can self-assemble into nanohydrogels than can encapsulate hydrophobic molecules in its inner core. ${ }^{\left[{ }^{[9]}\right.}$ The ratiometric response resulted from the interplay between a $\mathrm{pH}$ sensitive dye (bromothymol blue) and a couple of fluorescent probes (Coumarin 6 and Nile Red), which undergo FRET when confined into the nanogel (Fig. 15A). The nanogels were stable towards $\mathrm{pH}$ changes, which is critical to avoid large volume changes into the matrix that might influence the crosstalk between luminophores. In addition, control on the dyes ratio is essential for maintaining stability and output a balanced response at two different wavelengths. The versatility of this supramolecular "toolbox" can be further exemplified by the preparation of multianalyte ratiometric sensors of $\mathrm{pH}$ and oxygen. ${ }^{[00]}$ The self-assembly of Pluronic F-127 block copolymer in micelles conjugated with a fluorescein dye was employed in the encapsulation of an internal reference porphyrin probe $(5,10,15,20$-tetrakis-(pentafluorophenyl) porphyrin) and an oxygen sensor (platinum(II) mesotetraphenyltetrabenzoporphyrin). The nanosensor was finally stabilized by silica growth to yield multicomponent nanoparticles of $12 \mathrm{~nm}$ in diameter. The authors showed that $\mathrm{pH}$ and oxygen could be simultaneously determined in vitro using this single nano-probe. Furthermore, these nanoparticles sensors could be electroporated into cells without significant leakage or cytotoxicity. ${ }^{[90]}$ Different multivariable supramolecular sensors have also been employed to report on changes in the temperature ${ }^{[91]}$ or strain forces. ${ }^{[92]}$
The structural role of self-assembly has also been exploited for the attachment of fluorescent probes at a particular cellular location, such as the cell membrane. This could be of interest for the accurate quantification of $\mathrm{pH}$ values, at the proximity of the cancer cell surface membranes. ${ }^{\left[{ }^{[3]}\right.}$ Typically, the microenvironment at the outer surface of cancer cell membranes exhibits slightly lower $\mathrm{pH}$ values. This is consequence of an enhanced uptake of glucose and its fermentation to lactate in cancer cells, which is finally released to the extracellular environment. Therefore, $\mathrm{pH}$ measurements at the boundaries of cell membranes can be of great interest to track and monitor the local environment of therapeutic and cytotoxic molecules. In this regard, dye-conjugated lipidomimetics are optimal designs to restrict the fluorescent signal to the lipid bilayer. ${ }^{[94]}$ However, lipid flip-flop can hinder the identification of the leaflet location of the probe and cause wrong interpretation of the $\mathrm{pH}$ data. To tackle this challenge, new SNARF/peptide conjugates were developed to display $\mathrm{pH}$-dependent cell membranes insertion (Fig. 15B). ${ }^{[95]}$ The protonation of Asp/Glu residues enhanced peptide hydrophobicity and promoted folding and transmembrane helical insertion. These stimuli responsive peptide probes confirmed that the $\mathrm{pH}$ at the cell surface was sensitive to the glycolitic activity. A lowering of 0.7-0.6 units of $\mathrm{pH}$ was observed at the membrane outer leaflet and up to 1.3 units of $\mathrm{pH}$ for high metastatic cancer cells within the tumour environment, which was very heterogeneous. ${ }^{[95]}$ Membrane insertion of lipid-fluorophore covalent conjugates to report on cell membrane microenvironments has recently been updated with innovative linkers such as short single stranded $D N A^{[96]}$ or poly(ethylene)glycol polymers. ${ }^{[94]}$ Alternatively, covalent inclusion of recognition moieties, such as biotin-streptavidin partners, can be used for membrane anchoring biotinylated probes and allow ratiometric measurements. ${ }^{[97]}$ 


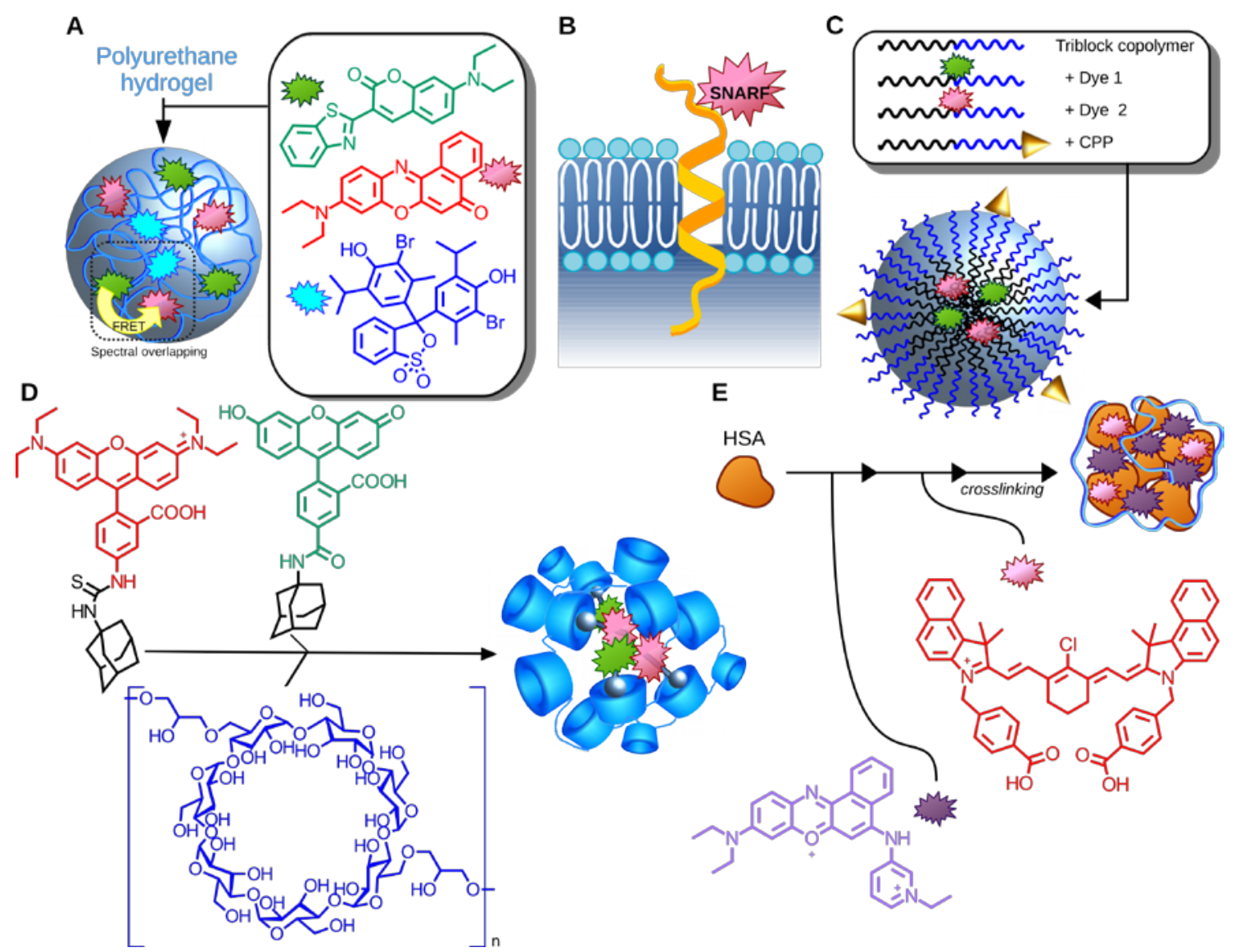

Figure 15. Examples of self-assembled probes for $\mathrm{pH}$ cellular measurements. A) Hydrogels that gather several fluorophores in a confined environment. B) Low $\mathrm{pH}$ insertion peptides for selective membrane $\mathrm{pH}$ imaging. C) Multicomponent micellar system including sensing and cell penetrating features. D) Ratiometric nanoprobes assembled by specific host-guest interactions $\left(M_{n} \approx 94400\right)$. E) Example of self-assembled system based dye-protein interactions.

\subsubsection{Micelles and liposomes}

Self-assembled systems have been also designed for the fabrication of concentration-independent ratiometric $\mathrm{pH}$ probes with potential application in the living cells. Gathering of molecular probes in confined volumes (such as the delimited by micelles and liposomes) has been widely exploited to bring together $\mathrm{pH}$-sensitive and reference fluorophores. ${ }^{[7]}$ These can be either covalently anchored to the self-assembling amphiphilic building blocks or encapsulated into the corresponding micelles or vesicles. Several of these strategies usually rely in the combination of building blocks bearing different probes with complementary properties that can be usually tuned by modulating the molar fraction of the building blocks in the functional ensemble. Accordingly, a mixture of poly(ethylene glycol)-b-poly(hydroxyethyl methacrylate) polymers bearing $\mathrm{pH}$ sensitive and reference fluorophores were self-assembled into micellar polymeric nanoparticles (diameter $\sim 50 \mathrm{~nm}$ ) for ratiometric $\mathrm{pH}$ quantification (Fig. 15C). ${ }^{[98]}$ A common problem of selfassembled sensing systems is the loss of structure and activity in biological media or after dilution. For example, micelle based sensors can be disassembled below their critical micellar concentration. In order to circumvent this problem, several strategies of copolymer micellar cross-linking have been proposed. ${ }^{[99]}$ For example, core cross-linked micelles were prepared by self assembly of an amphiphilic triblock copolymer, poly(ethylene glycol)-b-poly(2-amino ethyl methacrylate)- $b$ poly(coumarin methacrylate) (PEG-b-PAEMA-b-PCMA). ${ }^{[99]}$ Cross-linking was carried out by photochemical coumarin dimerization induced by UV irradiation. The $\mathrm{pH}$-dependent fluorescence signal was implemented by covalent immobilization 
of 2',7'-Bis-(2-carboxyethyl)-5-(and-6) carboxyfluorescein free acid and oregon green 488 isothiocyanate dyes (both $\mathrm{pH}$ sensitive), plus a reference dye Alexa Fluor 633 SUC. This ratiometric fluorescent probe was able to report and quantify a remarkable broad $\mathrm{pH}$ range (3.4-8.0). This unusual $\mathrm{pH}$ range might indicate that the fluorescent probes were allocated in environments of different chemical properties (e.g. different accessibility of water, presence of solvotropic effects, etc.). In another example, poly(ethylene glycol)- $b$-poly(2-aminoethyl methacrylate)- $b$-poly(styrene) (PEG- $b$-PAEMA- $b$-PS) micelles were self-assembled by slow displacement of DMF polymer solutions by water. Partial crosslinking ( $60 \%$ of the amines) was achieved by amidation with dicarboxylic acids, leaving a fraction of unreacted amine groups for anchoring $\mathrm{pH}$ sensitive and reference fluorophores such as fluorescein isothiocyanate, Oregon Green isothiocyanate and rhodamine B isothiocyanate ( $\mathrm{pH}$ insensitive). The probes were taken up by HeLa cells and ratiometric fluorescent measurements in the presence or absence of bafilomicine $\mathrm{A} 1$, an inhibitor of the proton pump, revealed that the probes were suitable to report on different degrees of acidification in vitro. ${ }^{[00]}$ In order to simplify the synthesis of these sensors, alternative methods relying on highly efficient synthetic methodologies (e.g. copper-catalyzed alkyneazide coupling) have also been reported. ${ }^{[01]}$ However, the higher stability achieved by covalent crosslinking comes with a penalty in the dynamic character of the supramolecular system, which is the source of unique and improved sensing capabilities (vide infra).

Maleimide keto-enol tautomerisms was also exploited for the development of ratiometric $\mathrm{pH}$ sensors made of poly $(\mathrm{N}$ phenylmaleimide) micelles. In this polymeric systems, the enolization and subsequent deprotonation of the maleimide moiety allowed the preparation of tricolor probes from green to red-shifted fluorescence emissions following the electron delocalization pattern (keto, $\lambda_{\mathrm{em}}=247 \mathrm{~nm}$ ), enol $\left(\lambda_{\mathrm{em}}=335 \mathrm{~nm}\right)$, enolate $\left.\left(\lambda_{\mathrm{em}}=431 \mathrm{~nm}\right)\right)$. The sensitivity of the polymeric micelles could be tuned by the inclusion of electron-withdrawing or electron-donating groups in the maleimide function. ${ }^{[102]}$ Other examples combine covalently-linked fluorescent dyes with encapsulated dyes: for instance, biocompatible tri-block copolymers (polyethylene glycol-polylisine-polyleucine) micelles with covalently attached fluorescein isothiocyanate and rhodamine-based (RBLC) encapsulated fluorophores. ${ }^{[103]}$ Chang et al reported the encapsulation of naphthalene diimides (NDIs) in hybrid nanoparticles that were prepared by self-assembly of polystyrene-block-poly(acrylic acid) into micelles followed by shell crosslinking with a silane derivative. ${ }^{[104]}$ The free carboxylic groups of the polymer were further functionalized with cell penetrating peptides. ${ }^{[105-108]}$ These nanoparticles showed fast $\mathrm{pH}$ response and cell internalization was observed in MCF-7 cells, where the distribution of the probe in cell organelles was strongly dependent on the incubation time. ${ }^{[104]}$

\subsubsection{Nanogels}

Nanogel encapsulation constitutes an excellent alternative for the biocompatible formulation of $\mathrm{pH}$ reporters. For instance, it can be used to isolate the probe from a complex environment preventing undesired side interactions and improving solubility. In addition to the example mentioned above, ${ }^{[84]}$ Cao et al demonstrated the inclusion into nanogels of 8-hydroxypyrene-1carbaldehyde, a ratiometric probe with a dual emission wavelength separation of ca $100 \mathrm{~nm}$. The potential interferences on the $\mathrm{pH}$ reporting capacities were ruled out by experiments in the presence of common intracellular species (e.g. $\mathrm{Ca}^{2+}, \mathrm{Fe}^{2+}$, metal cations, human serum albumin, glycine, etc.) at biological conditions. The nanogel probe was finally confirmed to be able to accurately report on the intracellular $\mathrm{pH} .{ }^{[109]}$

\subsubsection{Host-guest}

Supramolecular host-guest interactions are excellent tools for the design of smart multicomponent molecular devices that can be self-assembled in a controlled fashion. The versatility of the host-guest approach was exploited by $\mathrm{He}$ et al in a ratiometric $\mathrm{pH}$ probe composed of a $\beta-\mathrm{CD}$ polymer (host) and adamantaneanchored dyes (guests) (Fig. 15D). ${ }^{[110]}$ These building blocks were able to self-assemble into nanosized particles of around 30 $\mathrm{nm}$ of diameter. The inclusion of adamantane guests bearing $\mathrm{pH}$ sensitive and reference fluorophores (fluorescein and rhodamine B) allowed ratiometric analysis at an excellent $\mathrm{pH}$ range (8-4) for intracellular tracking. Increasing the functionality of these systems is relatively straightforward by including additional functional guests, such as targetting ligands. This has been exploited to carry out ratiometric mitocondrial $\mathrm{pH}$ measurements by adding an adamantane-labeled triphenylphosphonium guest. ${ }^{[111]}$ The versatility of this approach was extrapolated for ratiometric quantification of other analytes such as hydrogen sulfide $\left(\mathrm{H}_{2} \mathrm{~S}\right) .{ }^{[112]}$

\subsubsection{Proteins}

Interesting approaches to prepare protein-based ratiometric probes that generate fluorescence and photoacoustic read outs have also been recently reported (Fig. 15E). For example, human serum albumin (HSA) nanoaggregates were prepared by covalent crosslinking in the presence of two entrapped nearinfrared fluorophores, namely benzo[a]phenoxazine (BPOx, $\mathrm{pH}$ sensitive) and IR825 ( $\mathrm{pH}$ insensitive). The intratumoral and intravenous injections of these protein nanoprobes, in mice 4T1 tumor models, provided accurate $\mathrm{pH}$ measurements based on ratiometric photoacoustic or the fluorescent read outs. The 
photoacoustic emission of these near infrared probes allowed a deeper tissue penetration and better spatial resolution in the ratiometric $\mathrm{pH}$ imaging in animal tissues (up to $10 \mathrm{~mm}$ ). ${ }^{[86]}$ Furthermore, this intriguing strategy could be also applied in the photothermal ablation of tumours taking advantage of the NIR absorption profile on tissues. ${ }^{[113]}$

\subsection{Reporting role of the self-assembly}

$\mathrm{pH}$ triggered self-assembly can be used to prepare smart switches with applications sensing and bio-imaging. ${ }^{[114]}$ The incorporation of acidic or basic moieties into the monomeric building blocks of the supramolecular system triggers new opportunities to include protonation dependent repulsive or attractive forces in the final device. In these systems, the thermodynamic equilibrium between the different assembled states can be displaced by changes in the proton concentration.
In certain supramolecular designs, it is even possible to precisely shift between fully assembled or disassembled states as function of the $\mathrm{pH}$. This all or nothing behaviour can give rise to "on-off" pH switches ${ }^{[115]}$ that can exploit cooperative assembly effects. ${ }^{[116]}$ Emergent properties such as extremely narrow $\mathrm{pH}$ sensitivity can be observed in these dynamic supramolecular sensors. In this sense, there are a broad range of systems that can translate structural changes into spectroscopic changes such as DNA switches by changes in hybridization nucleotide hybridization have been studied to modulate the distance of cross-talking fluorophores. ${ }^{[117]}$ Several other exciting examples have employed the aggregation of dyes or the formation of segregated micellar phases to generate the fluorescent response, ${ }^{[118]}$ and other strategies exploit swelling changes of supramolecular systems upon protonation/deprotonation. ${ }^{[119]}$

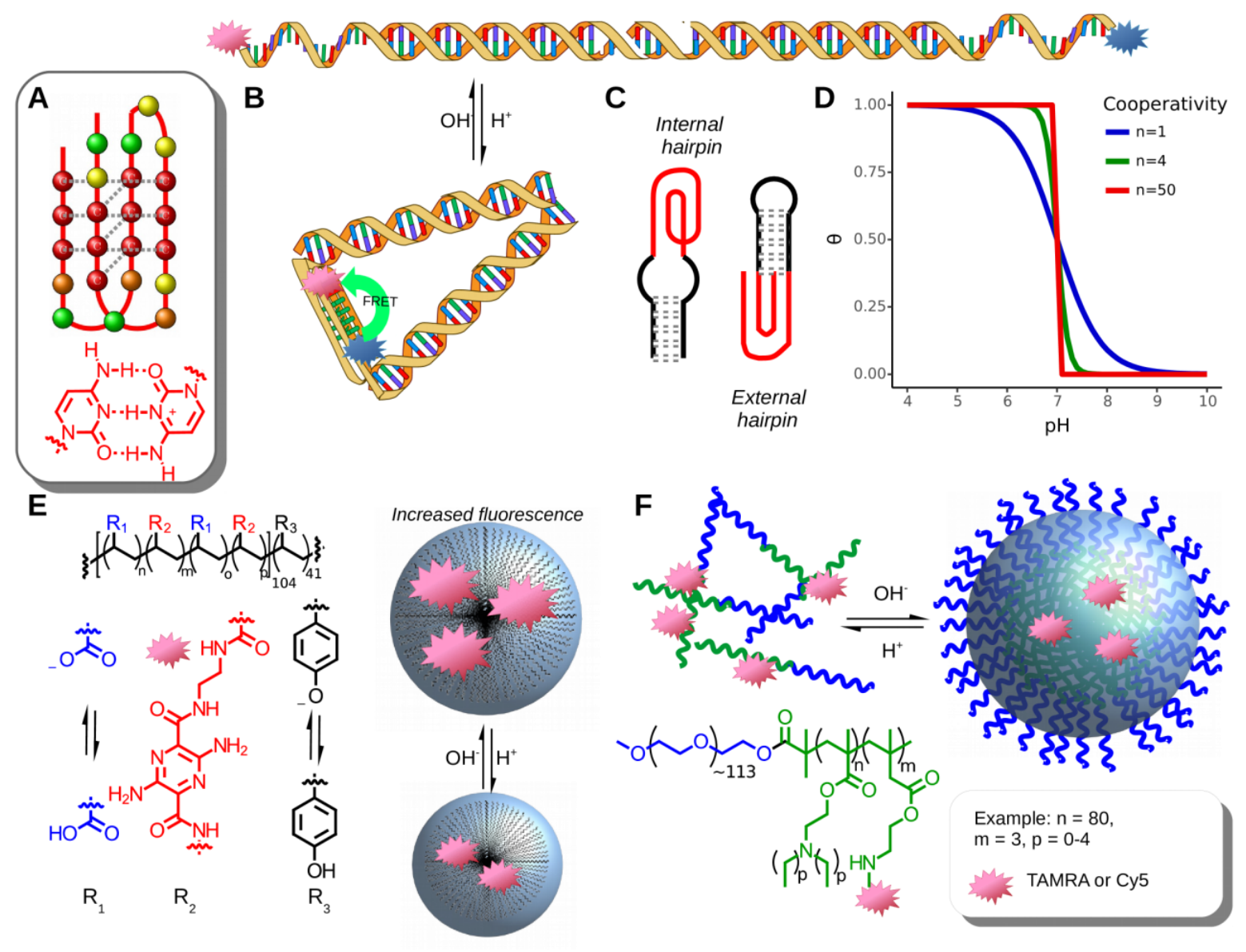

Figure 16. Examples of supramolecular switches for $\mathrm{pH}$ sensing. A) Schematic representation of the i-motif. B) DNA nanomachine that can monitor pH changes along the endocytic pathway. C) I-motifs showing internal or external hairpins. D) Protonation degree as function of $\mathrm{pH}$ in systems showing different degree of 
cooperativity. E) pH responsive micelle polymers that regulate the emission intensity through the swelling degree. F) UPS probes that show transistor-like reporting capabilities.

\subsubsection{DNA switches}

DNA sequence recognition and folding into different motives have been exploited as a highly versatile platform for the development of sensors for a variety of relevant analytes, e. g. for protein recognition. ${ }^{[120,121]}$ However, sensing of much simpler analytes such as protons can be achieved by exploiting nucleobase protonation. In this context, cytosine-rich nucleotide sequences can form a four-strand secondary structure, in which two parallel DNA duplexes are held together in an antiparallel fashion (Fig. 16A). Stabilization of these structures is due to cytosine hemiprotonation (generally at $\mathrm{pH}$ below 5) and formation of intercalated cytosine-cytosine base pairs. ${ }^{[122]}$ This type of secondary structure, referred as i-motifs, can be formed and destroyed by modifying the $\mathrm{pH}$ range close to physiological conditions. Additionally, it can be precisely controlled by different mechanism such as sequence engineering, chemical modification, cooperative self-assembly, external probes, etc. Therefore, this particular DNA supramolecular motif has been elegantly applied for the development of $\mathrm{pH}$ tracking probes. In a seminal report, Modi et al described a DNA design that alternates its conformation between open (extended) and i-motif (cyclic) state as a function of the $\mathrm{pH}$ (5-7.3) (Fig. 16B). This proton sensitive oligonucleotide was rationally labelled with donor/acceptor fluorescent pairs and the $\mathrm{pH}$-modulated switching of the DNA conformation was detected by FRET. ${ }^{[117]}$ This "I-switch" DNA nanomachine was capable of reporting on the acidification with spatiotemporal resolution along the endosomal maturation of the anionic ligand binding receptor (ALBR) pathway. Biotinylation of both the I-switch and a transferrin protein allowed the connection of the two macromolecules via a streptavidin host. This functional protein/DNA nanomachine allowed $\mathrm{pH}$ tracking during the receptor-mediated endocytic (RME) pathway of transferrin. ${ }^{[117]}$ These findings were further extended by the combination of two different DNA nanomachines intended to independently track the furin and transferrin endocytic pathways. To achieve protein specificity, the first DNA switch was conjugated to the transferrin protein to target the transferring receptor. The second DNA nanomachine included a DNA sequence that was recognized by a chimeric protein obtained by the fusion of furin and the corresponding DNA binding domain. Importantly, colocalization experiments in cells confirmed a low level of crosstalk between the individual nanomachines along the endocytic pathway. Furthermore, this dual switch was able to show that perturbations in organelle morphologies in early endosomes results in defective acidification. ${ }^{[123]}$ The uptake of these DNA nanomachines has been studied in a multicellular organism
(Caenorhabditis elegans). The nanosensors were targeted to the ALBRs pathway. These systems were finally employed to quantify the different $\mathrm{pH}$ values along the endocytic pathway, from the early endosomes to the lysosomes. ${ }^{[124]}$

Several groups have reported how structural modifications of DNA resulted in fine-tuning of the $\mathrm{pH}$ transition range and cooperativity in intriguing DNA supramolecular fluorescent energy transfer probes. A simplified way to quantify cooperative effects can be implemented in the classical HendersonHasselbalch equation ${ }^{[125]}$ :

$$
\log \left(\theta_{\mathrm{a}} / 1-\theta_{\mathrm{a}}\right) \approx \mathrm{n} \times(\mathrm{pKa}-\mathrm{pH}) \quad \mathrm{Eq}(1)
$$

where $\theta_{a}$ is the protonation degree, and $n$ is the Hill parameter that is used to take into account cooperativity. The effect of different degrees of cooperativity in the protonated fraction at different $\mathrm{pH}$ values is shown in Fig. 16D. An interesting consequence is that high cooperativity results in "on-off" responses that can be used to monitor with high precision specific $\mathrm{pH}$ thresholds. In this sense, minimal modifications of the core of the i-motif by alternation of $A / T$ stretches in between the cytidine tracks resulted in $\mathrm{pH}$ midpoint changes of as low as $0.15 \mathrm{pH}$ units. ${ }^{[126]}$ As a general rule, the longer the length of cytidine tracks, the narrower transition width, which can be rationalized by the higher number of protonation events in the imotifs with longer cytidine tracks. The transition midpoint could be further fine-tuned by including and additional allosteric control mechanism. Inclusion of internal or external hairpin motives was employed to enhance or decrease cooperativity respectively (Fig. 16C). ${ }^{[126]}$ DNA triplexes stabilized by $\mathrm{pH}$ sensitive Hoogsteen interactions were also employed as supramolecular $\mathrm{pH}$ sensors. ${ }^{[127]}$ The adjustment of the relative content of TAT/CGC triplets in this nucleotide-based sensor allowed the fast, precise

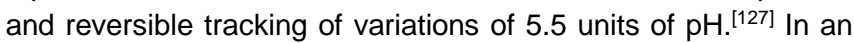
alternative strategy, the inclusion of chemically modified cytosines into critical points of the i-motif was exploited to modify the transition midpoint without affecting the overall cooperativity. ${ }^{[128]}$ The employed brominated or methylated cytosines showed a different pKa (2.5 and 4.7) than that of the cytosine N3 (4.45). As a consequence, the abrupt transition width was kept constant (2.0-3.3 Hill constant) over a range of transition midpoints (6.6-7.1) and the range of $\mathrm{pH}$ values that could be measured reliably was dramatically increased. 
Narayanaseamy et al proposed alternative adenine-rich oligonucleotide sequences for $\mathrm{pH}$ sensors intended to monitor small acidity ranges. ${ }^{[129]}$ At physiological conditions, the probe adopts a hairpin-like closed-state. Protonation of the adenine nucleobases triggers the formation of the extended conformation (A-motif). Attachment of cyanine dyes (3' and 5' ends) at the nucleotides terminal regions allows the signal transduction from conformational switch to FRET variations between the two probes. The system reported $\mathrm{pH}$ changes (between 3-5) with a rapid, efficient and reversible response. In another example, ratiometric reading was also achieved by a combination of an internal hairpin bearing a fluorophore and a quencher plus a complementary strand bearing a second different reference dye. At slightly alkaline $\mathrm{pH}$, the duplex predominates and the fluorophore attached to the complementary strand is quenched. However, at slightly acidic $\mathrm{pH}$, the i-motif DNA assembly quenched the signal of the fluorophore of the hairpin. Sharp transitions of $0.9 \mathrm{pH}$ units were observed and in vitro cell $\mathrm{pH}$ monitoring in SMMC-7721 cancer cell could be carried out at nanomolar probe concentrations. ${ }^{[130]}$

Nucleotide switches are intrinsically biocompatible $\mathrm{pH}$ sensors but they can be degraded by nuclease digestion. This situation compromises the stability and the lifetime of these probes in cells or living systems. Additionally, DNA uptake in cells can also be hindered by electrostatic repulsions between the phosphate backbone of the probe and the cell membrane anionic proteins and proteoglycans. Therefore, the inclusion of DNA into nanoparticle hybrid materials has been explored to enhance the stability and to improve the uptake of these DNA pH probes. In this regard, a gold nanoparticle-DNA hybrid system was designed to improve membrane translocation prevent enzymatic degradation of a $\mathrm{pH}$ sensitive i-motif nucleotide based $\mathrm{pH}$ probe $^{[131]}$ The structural changes of the i-motif modulated the distance between a fluorescent probe attached to one of the DNA strands and the gold nanoparticle, that acted as signal regulator by quenching of the fluorophore. Because the stability of the hybridized duplexes depends both on $\mathrm{pH}$ and temperature the probe response can be regulated by adjusting the binding strength between strands by mismatching base pairs of the nucleotide. In this way, a four-fold increase of fluorescence $(\mathrm{pH}$ 5 to 7) was observed at $37{ }^{\circ} \mathrm{C}$. Although theses probes partly accumulated on the cell lysosome, the nanoflares presented enhanced nuclease resistance. In another report, the attachment of two fluorescent probes, to a i-motif forming DNA strand not anchored to the nanoparticle surface, allowed the formation of a DNA closed state in where the cross talk between the two fluorophores was enabled. The relative fluorescence emission modulated by the FRET of the probes allowed $\mathrm{pH}$ ratiometric quantification in living cells. ${ }^{[132]}$ Electron microscopy and colocalization studies with organelle specific probes showed that the particles accumulated in the lysosome and the cytosol.
Electrostatic interactions between the anionic nucleotide and a positively charged polymer have been exploited in a simple noncovalent strategy for nanoparticles formulation. ${ }^{[133]}$ In this case, a duplex-triplex DNA switch (t-switch) was mixed with polyethylenimine $(\mathrm{PEI})$ to yield organic polyplexes of nanometric size $(20-50 \mathrm{~nm})^{[133]}$ The electrostatic interactions altered the performance of the t-switch, extending the $\mathrm{pH}$ response from 5.3-6 to 4.6-7.8 without significant alterations of the response kinetics. The resulting polyplexes were able to enter HepG2 cells in short times $(10 \mathrm{~min})$ and more efficiently than the corresponding naked t-switch control. The aggregation-triggered emission of dyes covalently linked to the proton sensitive i-motif has also been studied for DNA pH sensors. ${ }^{[134]}$ A water-soluble perylene dye was formulated within the extended oligonucleotide sequence. This open form provided binding sites to favour perylene aggregation and probe self-quenching. The protoninduced i-motif self-assembly triggered dye release, dilution and thus an enhancement of the radiative emission of the probe. ${ }^{[134]}$ The external control of the i-motif response has been recently studied by covalent attachment of light sensitive azobencene units to the DNA sequence. ${ }^{[135]}$

\subsubsection{Micelle triggers}

The application of micellar assemblies with a programmed "onoff" response towards $\mathrm{pH}$ changes has been studied for more than a decade. Conjugated or encapsulated fluorophores in micelles have been widely applied in stimuli responsive $\mathrm{pH}$ sensors. In general, the signal output is controlled by proton concentration or proximity of other fluorophores, although magnetic resonance readings have also been explored. ${ }^{[85]}$ Some early reports explored the combination of amines and fluorophores in order to modulate the extent of fluorophore charge transfer quenching as a function of the amine protonation. ${ }^{[136]}$ In a different strategy, the protonation of polymeric micelles and the subsequent disruption of the supramolecular assembly by cation repulsion was employed in the simultaneous $\mathrm{pH}$ tracking with concomitant release of encapsulated drugs ${ }^{[137]}$ or enhanced endosomal escape. ${ }^{[138]}$ Lee et al have shown that the emission of $\mathrm{pH}$ insensitive fluorophores can be controlled by the swollen degree of fluorophore-shell-crosslinked nanoparticles (Fig. 16E). ${ }^{[119]}$ Poly(acrylic acid)-b-poly( $p$-hydroxystyrene) diblock copolymers were self-assembled in water by dissolution of the copolymer in alkaline water followed by acidification to $\mathrm{pH} 7$. The resulting micelle was cross-linked with pirazine diamine as fluorophore. At basic $\mathrm{pH}$, the electrostatic repulsion between the deprotonated acrylic acid and p-hydroxystyrene moieties increased the swelling of the cross-linked micelles. In the final ensemble, the polymer protonation lowered the swelling and quenched the emission due to fluorophore aggregation. As expected, lower degrees of crosslinking allowed a higher fluorescence dynamic 
range. ${ }^{[119]}$ Self-assembly of multiblock polymers can be used to favour nanophase segregation affording compartmentalized nanostructures. Although these structures showed $\mathrm{pH}$ dependent emission changes, its photophysical properties are too complex for their straightforward use as $\mathrm{pH}$ sensors. ${ }^{[139]}$

These examples show micellar assembly changes can be exploited in sensing. However, the biological potential of these systems and the exploitation of cooperative behaviour have been developed more recently, and gave rise to exciting new properties. $^{[125]}$ An example are ultra-pH-sensitive (UPS) nanoprobes that exploit cooperative ${ }^{[140]}$ assembly. These are made of block co-polymers as shows Fig. 16F. The hydrophobicity of these amphiphilic co-polymers can be tuned by the incorporation of tertiary amines, where protonation/deprotonation allowed $\mathrm{pH}$-controlled micelle formation/disruption. The inclusion of fluorescent probes within the hydrophobic block, allowed the application of these micelles as "on-off transistors" due to fluorescence quenching in the aggregated state. ${ }^{[118]}$ This sharp "on-off" response was attributed to a highly cooperative deprotonation mechanism driven by hydrophobic phase separation, in where the polymers switch from fully protonated unimers to neutral micellar aggregates. ${ }^{[125]}$ This amplified response to minimal $\mathrm{pH}$ variations overcomes typical limitations found in traditional $\mathrm{pH}$ probes such as insensitivity to small $\mathrm{pH}$ ranges, photobleaching and signal fluctuations due to concentration effects. Due to these unique reporting properties, UPS probes have been used for the study of endosomes and lysosomes processes with an unprecedented sensitivity. ${ }^{[141]}$ The potential of these probes was demonstrated in a high-contrast in vivo tumour-imaging sensor. UPS probes allowed the precise monitoring of minimal $\mathrm{pH}$ differences, and allowed to image tumor extracellular milieu and angiogenic tumor vessels. ${ }^{[142]}$ Furthermore, the high buffering capacity of these type of polyamine micelles allowed simultaneous $\mathrm{pH}$ perturbation and imaging of ensosomal-associated regulation mechanisms. ${ }^{[143]}$ This technology allowed the determination of the $\mathrm{pH}$ thresholds required for activation of the cell growthsignaling pathway (mTORC1) and confirmed the mechanistic relationship between organelle acidification and accumulation of metabolite pools. Additionally, UPS probes could be adapted for broad-range detection of malignant tumours and image-guided surgery. ${ }^{[144]}$ Tri-block co-polymers hybrid micelles with three different ultrasensitive $\mathrm{pH}$ thresholds were developed to track the endosomal maturation with single organelle resolution. ${ }^{[145]}$ These experiments revealed a rich and highly dynamic evolution of the organelles along the endocytic pathway as well as the influence that mutated KRAS protoncogene had on the acidification rate of the endocytic organelle.

\subsubsection{Non-emissive aggregation of of luminophores}

Supramolecular interaction between luminophores frequently produces changes in the emissive properties. One of the bestknown processes is the aggregation-caused quenching (ACQ), in where the $\pi-\pi$ stacking between aromatic fluorophores causes the non-radiative relaxation of the excited states of the dyes. ${ }^{[146]}$ This quenching mechanism can be implemented in supramolecular systems to achieve on-off responses, minimize the noise as well as report on $\mathrm{pH}$ variations. For example, it has been reported that perylene bisimides with protonable secondary amine pendants are sensitive to quenching by aggregation and by electron transfer upon amine protonation. ${ }^{[147]}$ Conventional $\mathrm{pH}$ probes $^{[7]}$ have been chemically modified to allow the tuning of the aggregation state. In this sense, the protection of the hydroxyl group of the seminaphthorhodafluor (SNARF, Fig. 13) with apolar (i.e. p-acetoxybenzyl) quenched the probe emission by formation of nanoaggregates in where the SNARF was in the lactone form. The emission was recovered after catalytic ester hydrolysis in the presence of a esterase. ${ }^{[148]}$ A more detailed study showed that the assembly capabilities of SNARF could be rationalized according their hydrophobicity. ${ }^{[149]}$ Similar strategies have been applied to cyanines: the chemical modification of cyanines (Cy7) with aromatic moieties via imine formation was used to enhance the dye $\pi-\pi$ stacking affording quenched nanoparticles $(300 \mathrm{~nm})$ stable a neutral $\mathrm{pH}$. The hydrolysis of the imine bond at acidic $\mathrm{pH}$ caused particle disassembly and triggered the fluorescence emission of the cyanine in the near infrared. ${ }^{[150]}$ The $\pi-\pi$ and the cation- $\pi$ interactions of small aromatics molecules can also be employed for monitoring small and precise variations of the $\mathrm{pH}$. For example, diketopyrrolopyrrole bearing quaternary ammonium branches has been used for imaging tumours in vivo. ${ }^{[151]}$ These probes showed sharp assembly transitions between $\mathrm{pH}$ values of 6.8-7, which make them useful to differentiate normal tissues and the slight more acidic environment of the extra-tumour tissue. pH-dependent quenching of fluorophores by carbon nanotubes have also been described such as in pyrenepoly(sulfadimethoxine methacrylamide (PSDM) conjugated to carbon nanotubes. When protonated, the PSDM polymer adopted an extended conformation due to its increased water solubility. When the $\mathrm{pH}$ was below the pKa of the polymer, the pyrene moiety collapsed on the carbon nanotube surface and its emission was fully quenched by intramolecular charge transfer. ${ }^{[152]}$ 
A

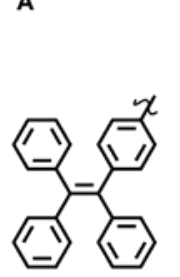

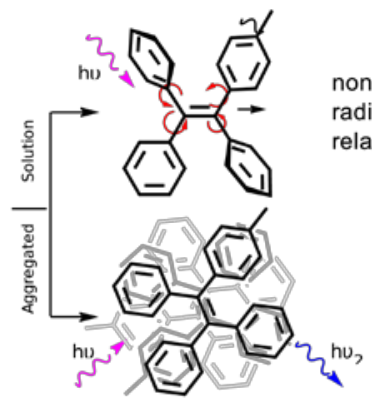

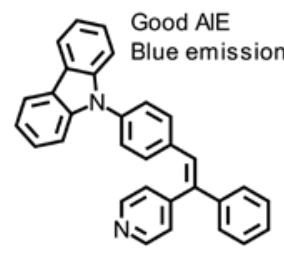

radiative

B
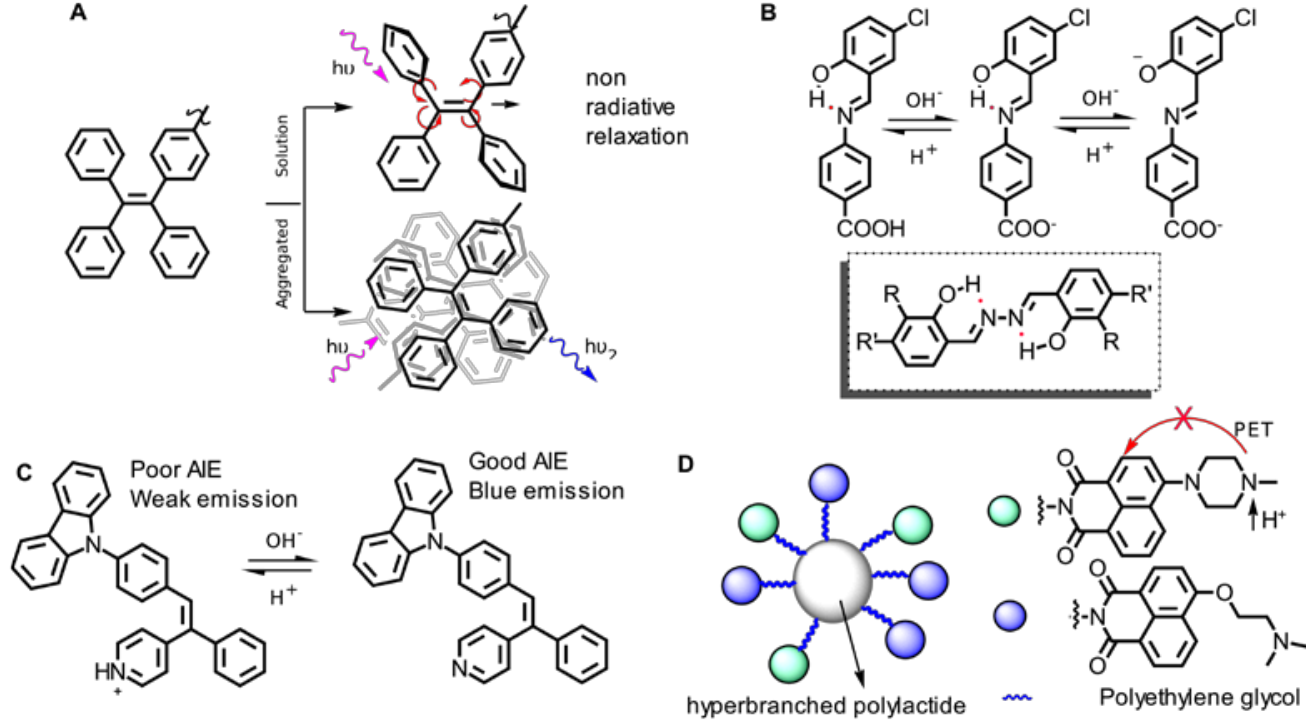

Figure 17. Examples of probes based on AIE for pH sensing: A) Response of the 1,1,2,2-tetraphenylethylene when homogeneously dissolved or in aggregated state. B) Examples of Schiff bases with AIE properties that were used for $\mathrm{pH}$ sensing: top, 4-carboxylaniline-5-chlorosalicylaldehyde. Bottom. salicylaldehyde azines, where R and R' denote substitution points with different groups $\left(\mathrm{H}, \mathrm{NO}_{2}, \mathrm{Cl}, \mathrm{MeO}, \mathrm{Et}_{2} \mathrm{~N}\right)$. Red bonds denote hydrogen bonding formed between the fenolic alcohol and the imine/azine nitrogen. C) 1-(4-Pyridinyl)-1-phenyl-2-(9-carbazolyl)ethene. Emission of this probe switches from blue to dark upon protonation/deprotonation. D) Hyperbranched polylactide nanoparticles functionalized with the naphthalimide-based fluorophores.

\subsubsection{Emissive aggregation of luminophores}

Certain luminophores emit fluorescence upon self-assembly by aggregation-induced emission (AIE). This phenomena was also observed during the purification of 1-methyl-1,2,3,4,5pentaphenylsilole that was not luminescent in ethanol. ${ }^{[153]}$ However, when diluted with water, the aggregation of the pentaphenyl molecule enhanced the fluorescence emission by two orders of magnitude. This enhancement of emission was explained in terms of molecular packing and planarization of the hindered pentaphenylsilole. Early reports of AIE-based $\mathrm{pH}$ sensors were based in 9,10-distyrylanthracene that was quenched in organic solvents such as acetonitrile. ${ }^{[154]}$ The fluorescence emission of the probe was triggered when the percentage of water in the solution was higher than $60 \%$ and DLS and SEM revealed the formation of nanoaggregates of 100$150 \mathrm{~nm}$ in size. In addition, the aggregation of the anthracene probe could be modulated by $\mathrm{pH}$ changes in acetonitrile-water mixtures. The emission turning on was also observed upon interaction with biomolecules such as proteins and DNA. ${ }^{[154]}$ Since its discovery, the sensing applications of AIE have grown exponentially including in cell and tissue imaging, and several different structural motives have demonstrated to by suitable for such end. ${ }^{[155]}$
Tetraphenylethylene (TPE). TPE is a conventional example of polycyclic system showing AIE properties and it has been applied in $\mathrm{pH}$ sensing inside cells. ${ }^{[156]}$ Chen et al reported sensor combining a cyanine dye (reference) with a $\mathrm{pH}$ sensitive AIEgen TPE unit (25). ${ }^{[31]}$ In solution, the rotation of the aromatic rings around the central axis of the ethyelene unit quenches the fluorescence. After aggregation, this rotation is restricted and the fluorescence emission is recovered (Fig. 17A). ${ }^{[157]}$ The TPE/cyanine conjugate allowed wide-range $\mathrm{pH}$ ratiometric measurements allowing simultaneous measurements of acidic (lisosomes) or alkaline (mitochondria) organelles. Interestingly, the pKa was strongly affected due to the stabilization of the probe within the lipid membrane of the cells. ${ }^{[156]}$ Introducing simple chemical modifications, such as the attachment of protonable amino acids, can modulate the aggregation degree of tetraphenylethylene. These modifications allowed the $\mathrm{pH}$ control of the fluorescence response and the application of these probes in $\mathrm{pH}$ and protein sensing. ${ }^{[158]}$ Tetraphenylethyleneoxazolidine conjugates also showed switchable $\mathrm{pH}$ dependent emission due to intramolecular charge transfer. This probe was attached to PEG-polyestyrene copolymers that self-assembled into stable micelles. The resulting nanoparticles were employed to track the intracellular $\mathrm{pH}$ differences in HepG2 cells. ${ }^{[159]}$ 
Schiff bases. Different Schiff bases with AIE properties have been reported in the last decade. For example, 4carboxylaniline-5-chlorosalicylaldehyde (Fig. 17B, top) shows complex emissive properties depending on the $\mathrm{pH}$. The first spectral change occurs upon deprotonation, from $\mathrm{pH} 3.4$ to $\mathrm{pH}$ 5.6, of the carboxylic acid, which triggers a decrease in fluorescence emission $\left(\square_{\mathrm{em}}=559 \mathrm{~nm}\right.$ ). This change was attributed to the dissolution of dye aggregates. In this sense, the formation of an internal hydrogen bond in the salicylaldimine moiety, only possible at acidic $\mathrm{pH}$, is essential to stop the free rotation of the probe, as supported by X-ray experiments. Additionally, this probe shows a second spectral change observed as an increase of the fluorescence emission from $\mathrm{pH}$ 5.6 to $9.6(\square \mathrm{em}=516 \mathrm{~nm})$. This was attributed to the enhanced intramolecular charge transfer of the deprotonated enolate. Because the spectral changes occur at $\mathrm{pH}$ ranges relevant in biological media, ratiometric $\mathrm{pH}$ measurements in HepG2 cells could be carried out with negligible toxicity. ${ }^{[160]}$ Further studies on salicylaldehyde Schiff-base derivatives revealed that inclusion of electron withdrawing groups in the fenol ring influenced both the emission color (green to red) and the $\mathrm{pH}$ response. Irreversible quenching of the fluorescence suggested that the probes could be undergoing hydrolysis. ${ }^{[161]}$ On the other hand, pyrene derivatives conjugated with Schiff bases have shown a distinctive "on-off" response at highly acidic $\mathrm{pH}$ (1-3). The observed green emission was attributed to pyrene aggregation and not to the hydrolysis of the Schiff base. ${ }^{[162]}$ Salicylaldehyde azines have also been explored as potential ratiometric probes for $\mathrm{pH}$ sensing (Fig. 17B, insert). ${ }^{163]}$

Bis-pyrenes. Bis-pyrenes are remarkable fluorophores than can be elaborated or integrated into more complex systems which exhibit unique photochemical properties. ${ }^{[164]}$ For example, these systems can be non-covalently conjugated to $\mathrm{pH}$ responsive amphiphilic polymers by hydrophobic interactions. ${ }^{[165]}$ These hybrid systems were formed by micellar assemblies at neutral $\mathrm{pH}$ that dissociated at $\mathrm{pH} 5.5$ (i.e. Iysosomes). Upon acidification, the disassembly of the micelles and the aggregation of the bis(pyrene) in the aqueous environment triggered a 6-fold increase of the fluorescence emission. Experiments in HeLa cells showed that the probe accumulated in the lysosome and thus the emission increased with the incubation time. The presence of the aggregates inside the cells was confirmed by electron microscopy (TEM) after lysis of the cells. ${ }^{[165]}$

Others. Combining carbazolyl and piridyl units Yang et al have prepared an organic fluorophore that showed AIE properties and intramolecular charge transfer (Fig. 17C). ${ }^{[166]}$ This probe was used for $\mathrm{pH}$ sensing with a remarkable 80 -fold enhancement of the emission from $\mathrm{pH} 1$ to 12 in the aggregated state. ${ }^{[166]}$ In a related example, 4'-(p-tolyl)-2,2':6',2"-terpyridine was quenched when dissolved in DMSO but yellow fluorescence was observed after the addition of water. The emission in the aqueous solutions could be quenched by protonation and reactivated by alkalinization. These hydrophobic dyes were able to enter the cell with the assistance of ionic amphiphiles. After membrane translocation, the emission observed in the cells shifted from yellow to green, a situation that was attributed to the $\mathrm{pH}$ changes inside the cell. ${ }^{[167]}$ Bao et al have proposed tuneable fluorescent $\mathrm{pH}$ sensor based on hyperbranched polylactide nanoparticles functionalized with the naphthalimide-based fluorophores (Fig. 17D). The conjugation of these particles with blue (reference) and green ( $\mathrm{pH}$ sensitive) naphthalimide fluorophores allowed the preparation of a set of ratiometric fluorescent polymers. Detection of protons was achieved due to photoinduced electron transfer (PET) from a piperazine pendant to the naphthalimide of the green fluorophore. $\mathrm{pH}$ measurements at a physiological relevant range (5-8) were accomplished by adjusting the ratio between the blue and green naphthalimide dyes. This nanoparticle sensor was taken up by HeLa cells allowing the tracking of the lysosome $\mathrm{pH}^{\left[{ }^{[168]}\right.}$

\subsubsection{Proteins}

Proteins are highly appealing biological sensors as they are biocompatible and can be genetically encoded and expressed. ${ }^{[169]}$ Recent examples demonstrated that genetically encoded protein $\mathrm{pH}$ probes can be employed to image cellular compartments. ${ }^{[170]}$ The balance between covalent and noncovalent forces in protein-dye hybrids was used to develop fluorescent ratiometric probes for intracellular $\mathrm{pH}$. Interactions between serum albumin and squaraine dye nanoparticles were employed to control the assembly degree of the hybrid nanosized system. This sensor showed green emission at basic $\mathrm{pH}$ due to the nucleophilic attack of the thiol groups of BSA cysteine residues to the squarine fluorophores. On the other hand, in acidic media the strong non-covalent interactions of BSA with the squaline molecule resulted in a red-shifted fluorescence emission. The green/red emission ratio strongly depended on the chosen BSA/squarine stoichiometry. The fine-tuning of the $\mathrm{BSA} / \mathrm{squarine}$ molar ratio allowed the preparation of an array of wide-range and precise intracellular $\mathrm{pH}$ probes. ${ }^{[171]}$ In a recent example, the mTurquoise 2 and mNeonGreen FRET pair of fluorescent proteins was electrostatically attached to the surface of mesoporous silica nanoparticles at acidic $\mathrm{pH}$. The electrostatic interaction of the proteins with the particles was disrupted after alkalinization and thus the FRET signal quenched. This "in situ" assembling $\mathrm{pH}$ sensor showed a linear response for $\mathrm{pH}$ detection in the range of 5.5-8.0. ${ }^{[172]}$ 


\section{Conclusions}

Tracking the $\mathrm{pH}$ with spatiotemporal resolution in biological systems is a critical challenge for chemical biology and beyond. Over the last two decades different small molecular probes and supramolecular systems have emerged for in cellulo or in vivo $\mathrm{pH}$ detection. Recent conceptual strategies have tackled and resolved several important limitations of the field such as widerange $\mathrm{pH}$ reporting, precise $\mathrm{pH}$ "on-off" responses, interference or sensitivity to physiological components, uptake in living cells, etc. However, although much has been advanced, $\mathrm{pH}$ reporting in living systems still presents critical limitations such as background reduction, sensor improved stability, low impact into the host (cell, tissue) function, tissue and/or organelle targeting, endosomal escape, medium and far infrared ratiometric $\mathrm{pH}$ tracking, adaptation of the probes to the next generation imaging techniques (i.e. super-resolution), etc. It is clear that these challenges will demand the combined efforts of synthetic and supramolecular chemistry working together to develop new and improved smart materials that will resolve the current limitations. The synthesis of new molecular fluorophores is necessary to fabricate new probes with improved and complementary capabilities new supramolecular designs will be required for the precise control of the fluorophore response. The joint efforts of these two disciplines will allow the preparation of completely controlled molecular structures with precise stimuli responsive capabilities for accurate $\mathrm{pH}$ reporting in cells and living tissues. This review matches the recent advances in the synthesis of the probes and the supramolecular designs that will illuminate the bright future of this essential field of chemistry and biology.

\section{Acknowledgements}

This work was partially supported by the Spanish Agencia Estatal de Investigación (AEI) [SAF2017-89890-R], the Xunta de Galicia (ED431C 2017/25, 2016-AD031 and Centro Singular de Investigación de Galicia accreditation 2016-2019, ED431G/09), the ISCIII (RD16/0008/003), and the European Union (European Regional Development Fund - ERDF). A.M. received a Marie Curie fellowship (GLYCONANOPEP-750248). J.M. received a Ramón y Cajal (RYC-2013-13784), an ERC Starting Investigator Grant (DYNAP-677786) and a Young Investigator Grant from the Human Frontier Science Research Program (RGY0066/2017).
Dr. Montenegro obtained his PhD degree in 2009 after two predoctoral stays in Cambridge (Prof. Steven V. Ley) and Scripps (Prof. Reza Ghadiri). He was a post-doc in the University of Geneva with Prof. Stefan Matile (20092012). Dr. Montenegro returned to the Spanish academia in 2012 and achieved a Ramon y Cajal contract and a PI position in the CIQUS institute in Santiago de Compostela. In 2015 he was awarded with ERC Starting Grant and in 2016 with a Human Frontiers Research Grant for Young Investigators. The Montenegro group research interest lays at the interphase between organic synthetic and supramolecular chemistry applied to biological systems and the discovery of new materials. Focused in supramolecular assemblies with applications in chemical and synthetic biology such as nucleic acids delivery, cytosolic protein controlled release and self-assembled tubular-templated composites for simple synthetic cytoskeleton mimics. Dr. Montenegro has been recently awarded with the Prize of Young Investigators of the Spanish Royal Society of Chemistry (2018) and the Prize of Young Research Group Leaders in Chemical Biology of the RSEQ (2019).

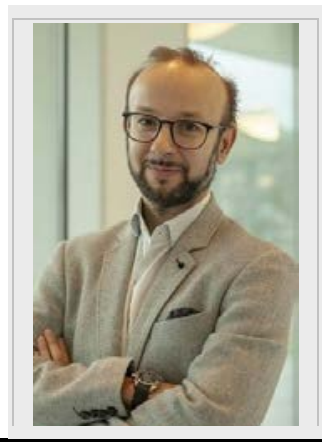

Dr. Alejandro Méndez-Ardoy carried out his Ph. D. studies at the University of Seville (2011). He carried out two predoctoral stays in the University of Pamplona (Prof. Tros de llarduya) and in University of Nize (Prof. Pierre Vierling). He carried out two postdoctoral stays in Netherlands and France: University of Twente-MESA+ (Prof. Jurriaan Huskens), and at L'Institute des Sciences Moléculaires-University of Bordeaux (Prof. Dario M. Bassani). He has recently achieved the prestigious Marie Curie postdoctoral fellowship in the Montenegro group, where he develops microfluidics systems and new supramolecular self-assembled materials towards bottom up approaches in syntehtic biology.

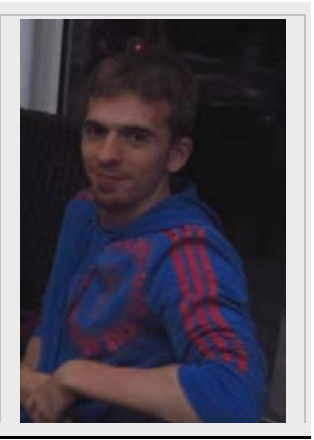


Dr. Reina obtained his PhD degree in 2008 at the Chemical Research Institute CSIC-University of Seville. He carried out two predoctoral stays in IBS-Institut de Biologie Structurale (Prof. Frank Fieschi) and University of Milan (Prof. Anna Bernardi). He continued in Milan with a post-doctoral stay and the prestigious Marie Curie IEF in the group of Prof. Anna Bernardi in glycoconjugates. Dr. Reina achieved the JAE-DOC contract (2013-2015) and he returned to the Chemical Research Institute in Seville and in 2016, he moved to Santiago de Compostela as Research Associate in the group of Dr. Montenegro to work in synthetic strategies towards penetrating glycopeptides and $\mathrm{pH}$ ratiometric fluorescent probes. He is vice-chair of the Innogly COST action (Action CA18103).
Keywords: keyword $1 \bullet$ keyword $2 \cdot$ keyword $3 \bullet$ keyword 4 • keyword 5

[1] L. D. Lavis, R. T. Raines, Acs Chem. Biol. 2008, 3, 142-155. [2] J. Rao, A. Dragulescu-Andrasi, H. Yao, Curr. Opin. Biotech. 2007, 18, 17-25.

[3] M. Chalfie, Y. Tu, G. Euskirchen, W. W. Ward, D. C. Prasher M. Chalfie, Y. Tu, G. Euskirchen
Science 1994, 263, 802-805.

[4] P. J. Bosch, I. R. Corrêa, M. H. Sonntag, J. Ibach, L. Brunsveld, J. S. Kanger, V. Subramaniam, Biophysical Journal 2014, 107, 803-814.

[5] T. Terai, T. Nagano, Pflugers Arch. 2013, 465, 347-359.

[6] A. S. Klymchenko, Acc. Chem. Res. 2017, 50, 366-375.

[7] J. Han, K. Burgess, Chem. Rev. 2010, 110, 2709-2728.

[8] M. S. Briggs, D. D. Burns, M. E. Cooper, S. J. Gregory, Chem. Commun. 2000, 2323-2324.

[9] R. P. Haugland, The Handbook: a Guide to Fluorescent Probes and Labeling Technologies, 2005.

[10] N. Marcotte, A. M. Brouwer, J. Phys. Chem. B 2005, 109, $11819-11828$.

[11] A. K. Galande, R. Weissleder, C.-H. Tung, Bioconjugate Chem. 2006, 17, 255-257.

[12] N. Boens, V. Leen, W. Dehaen, Chem. Soc. Rev. 2012, 41 1130-1172.

[13] Y. Xu, Y. Liu, X. Qian, J. Photochem. Photobiol., A: Chemistry 2007, 190, 1-8.

[14] X.-J. Cao, L.-N. Chen, X. Zhang, J.-T. Liu, M.-Y. Chen, Q.-R. Wu, J.-Y. Miao, B.-X. Zhao, Anal. Chim. Acta 2016, 920, 8693. A. P. de Silva, H. Q. N. Gunaratne, T. Gunnlaugsson, A. J. M Huxley, C. P. McCoy, J. T. Rademacher, T. E. Rice, Chem. Rev. 1997, 97, 1515-1566.

[16] S. T. Manjare, Y. Kim, D. G. Churchill, Acc. Chem. Res. 2014 47, 2985-2998.

[17] P. Bhattarai, Z. Dai, Adv. Healthcare Mater. 2017, 6, 1700262
1700223.

H. A. Shindy, Dyes and Pigments 2017, 145, 505-513.

M. Panigrahi, S. Dash, S. Patel, B. K. Mishra, Tetrahedron 2012, 68, 781-805.

F. Würthner, S. Yao, J. Org. Chem. 2003, 68, 8943-8949.

S. Kaloyanova, V. M. Trusova, G. P. Gorbenko, T.

Deligeorgiev, J. Photochem. Photobiol., A: Chemistry 2011. 217, 147-156.

D. S. Pisoni, L. Todeschini, A. C. A. Borges, C. L. Petzhold, F S. Rodembusch, L. F. Campo, J. Org. Chem. 2014, 79, 55115520.

O. P. Klochko, I. A. Fedyunyayeva, S. U. Khabuseva, O. M. Semenova, E. A. Terpetschnig, L. D. Patsenker, Dyes and Pigments 2010, 85, 7-15.

L. M. Yagupolskii, O. I. Chernega, N. V. Kondratenko, A. N. Chernega, Y. G. Vlasenko, R. V. Nedelkov, Y. L. Yagupolskii, Journal of Fluorine Chemistry 2010, 131, 165-171. M. E. Cooper, S. Gregory, E. Adie, S. Kalinka, J. Fluoresc. 2002, 12, 425-429.

Z. Zhang, S. Achilefu, Chem. Commun. 2005, 3, 5887-3. S. A. Hilderbrand, K. A. Kelly, M. Niedre, R. Weissleder, Bioconjugate Chem. 2008, 19, 1635-1639.

B. Tang, X. Liu, K. Xu, H. Huang, G. Yang, L. An, Chem. Commun. 2007, 3726-3728.

B. Tang, F. Yu, P. Li, L. Tong, X. Duan, T. Xie, X. Wang, J. Am. Chem. Soc. 2009, 131, 3016-3023.

T. Myochin, K. Kiyose, K. Hanaoka, H. Kojima, T. Terai, T. Nagano, J. Am. Chem. Soc. 2011, 133, 3401-3409.

S. Chen, J. Liu, Y. Liu, H. Su, Y. Hong, C. K. W. Jim, R. T. K. Kwok, N. Zhao, W. Qin, J. W. Y. Lam, et al., Chem. Sci. 2012, 3, 1804-1809

L. Fan, Y.-J. Fu, Q.-L. Liu, D.-T. Lu, C. Dong, S.-M. Shuang, Chem. Commun. 2012, 48, 11202-11204.

J. Wang, S. Xia, J. Bi, M. Fang, W. Mazi, Y. Zhang, N. Conner, F.-T. Luo, H. P. Lu, H. Liu, Bioconjugate Chem. 2018, 29, 1406-1418. Anal Chem 2015, 87, 2495-2503. X. Zhu, L. Yuan, X. Hu, L. Zhang, Y. Liang, S. He, X.-B. Zhang W. Tan, Sensor Actuat. B-Chem. 2018, 259, 219-225. D. Xu, Y. Li, C.-Y. Poon, H.-N. Chan, H.-W. Li, M. S. Wong, Anal. Chem. 2018, 90, 8800-8806.

[37] S. Xia, J. Wang, J. Bi, X. Wang, M. Fang, T. Phillips, A. May, N. Conner, M. Tanasova, F.-T. Luo, et al., Sensor Actuat. BChem. 2018, 265, 699-708.

[38] D. Dahal, L. McDonald, X. Bi, C. Abeywickrama, F. Gombedza M. Konopka, S. Paruchuri, Y. Pang, Chem. Commun. 2017, 53, 3697-3700 Z. Li, E. Mintzer, R. Bittman, J. Org. Chem. 2006, 71, 17181721.

V. P. Yakubovskyi, M. P. Shandura, Y. P. Kovtun, Eur J Org Chem 2009, 2009, 3237-3243.

L. Wu, K. Burgess, Chem. Commun. 2008, 107, 4933-4935. R. W. Wagner, J. S. Lindsey, Pure Appl. Chem. 1996, 68, 1373-1380.

M. Shah, K. Thangaraj, M. L. L. Soong, L. T. Wolford, J. H. Boyer, Heteroatom Chem. 1990, 1, 389-399.

T. Werner, C. Huber, S. Heinl, M. Kollmannsberger, J. Daub, O. S. Wolfbeis, Fresenius J. Anal. Chem. 1997, 359, 150-154. M. Baruah, W. Qin, N. Basarić, W. M. De Borggraeve, N. Boens, J. Org. Chem. 2005, 70, 4152-4157.

Y. Urano, D. Asanuma, Y. Hama, Y. Koyama, T. Barrett, M. Kamiya, T. Nagano, T. Watanabe, A. Hasegawa, P. L. Choyke et al., Nat. Med. 2008, 15, 104-109.

M. Zhu, P. Xing, Y. Zhou, L. Gong, J. Zhang, D. Qi, Y. Bian, H. Du, J. Jiang, J. Mat. Chem. B 2018, 6, 4422-4426.

H. Xiong, P. Kos, Y. Yan, K. Zhou, J. B. Miller, S. Elkassih, D. J. Siegwart, Bioconjugate Chem. 2016, 27, 1737-1744.

M. Grossi, M. Morgunova, S. Cheung, D. Scholz, E. Conroy, M. Terrile, A. Panarella, J. C. Simpson, W. M. Gallagher, D. F. O'Shea, Nat. Commun. 2016, 7, 10855.

[50] A. Sutter, M. Elhabiri, G. Ulrich, Chem. Eur. J. 2018, 24 11119-11130. 
W.-C. Sun, K. R. Gee, D. H. Klaubert, R. P. Haugland, J. Org. Chem. 1997, 62, 6469-6475.

J. Shi, X. Zhang, D. C. Neckers, J. Org. Chem. 1992, 57, 4418-4421.

V. P. Boyarskiy, V. N. Belov, R. Medda, B. Hein, M. Bossi, S. W. Hell, Chem. Eur. J. 2008, 14, 1784-1792.

J. E. Whitaker, R. P. Haugland, D. Ryan, P. C. Hewitt, F. G. Prendergast, Anal. Biochem. 1992, 207, 267-279. C. C. Woodroofe, M. H. Lim, W. Bu, S. J. Lippard, Tetrahedron 2005, 61, 3097-3105.

S. C. Burdette, S. J. Lippard, Inorg. Chem. 2002, 41, 68166823.

A. S. Chaudhari, Y. S. Parab, V. Patil, N. Sekar, S. R. Shukla, RSC Adv. 2012, 2, 12112-12117.

J. B. Grimm, L. D. Lavis, Org. Lett. 2011, 13, 6354-6357.

J. E. T. Corrie, J. S. Craik, 1995, WO95/09170.

Y. M. Cheng, T. Kelly, J. Church, Neuroscience 2008, 151, 1084-1098.

X.-L. Wu, X.-L. Jin, Y.-X. Wang, Q.-B. Mei, J.-L. Li, Z. Shi, J. Lumin. 2011, 131, 776-780.

F.-Y. Ge, X.-L. Yan, F.-Y. Yan, H.-Y. Pan, L.-G. Chen, J.

Fluoresc. 2005, 15, 829-833.

E. Nakata, Y. Nazumi, Y. Yukimachi, Y. Uto, H. Maezawa, T. Hashimoto, Y. Okamoto, H. Hori, Bioorg. Med. Chem. Lett. 2011, 21, 1663-1666.

Z. Li, S. Wu, J. Han, S. Han, Analyst 2011, 136, 3698-3706. X. Chen, T. Pradhan, F. Wang, J. S. Kim, J. Yoon, Chem. Rev. 2012, 112, 1910-1956.

E. E. Nekongo, P. Bagchi, C. J. Fahrni, V. V. Popik, Org. Biomol. Chem. 2012, 10, 9214-9218.

D. Asanuma, Y. Takaoka, S. Namiki, K. Takikawa, M. Kamiya, T. Nagano, Y. Urano, K. Hirose, Angew. Chem. Int. Ed. 2014 $53,6085-6089$.

S. Takahashi, Y. Kagami, K. Hanaoka, T. Terai, T. Komatsu, T. Ueno, M. Uchiyama, I. Koyama-Honda, N. Mizushima, T. Taguchi, et al., J. Am. Chem. Soc. 2018, 140, 5925-5933. Z. Xue, H. Zhao, J. Liu, J. Han, S. Han, ACS Sens. 2017, 2, 436-442.

X. Wan, S. Liu, J. Mater. Chem. 2011, 21, 10321-10329.

S. Benson, A. Fernandez, N. D. Barth, F. de Moliner, M. H. Horrocks, C. S. Herrington, J. L. Abad, A. Delgado, L. Kelly, Z. Chang, et al., Angew. Chem. Int. Ed. 2019, 58, 6911-6915. Y. Wen, W. Zhang, T. Liu, F. Huo, C. Yin, Anal. Chem. 2017, 89, 11869-11874.

Z. Xie, B. Yin, J. Shen, D. Hong, L. Zhu, J. Ge, Q. Zhu, Org. Biomol. Chem. 2018, 16, 4628-4632.

J.-T. Hou, W. X. Ren, K. Li, J. Seo, A. Sharma, X.-Q. Yu, J. S. Kim, Chem. Soc. Rev. 2017, 46, 2076-2090.

A. Fernandez, M. Vendrell, Chem. Soc. Rev. 2016, 45, 11821196.

O. Seksek, N. Henry-Toulmé, F. Sureau, J. Bolard, Anal. Biochem. 1991, 193, 49-54.

K. Nienhaus, G. Ulrich Nienhaus, Chem. Soc. Rev. 2014, 43 1088-1106.

A. S. Klymchenko, R. Kreder, Chem. Biol. 2014, 21, 97-113.

Y. S. Marfin, E. L. Aleksakhina, D. A. Merkushev, E. V. Rumyantsev, I. K. Tomilova, J. Fluoresc. 2016, 26, 255-261. M. Collot, P. Ashokkumar, H. Anton, E. Boutant, O. Faklaris, T. Galli, Y. Mely, L. Danglot, A. S. Klymchenko, Cell Chem. Biol. 2019, 26, 600-614.e7.

M. Tantama, Y. P. Hung, G. Yellen, J. Am. Chem. Soc. 2011 133, 10034-10037. G. Miesenböck, D. A. De Angelis, J. E. Rothman, Nature 1998 , 394, 192-195.

D. Williams, M. Westwell, Chem. Soc. Rev. 1998, 27, 57-64. H.-S. Peng, J. A. Stolwijk, L.-N. Sun, J. Wegener, O. S Wolfbeis, Angew. Chem. Int. Ed. 2010, 49, 4246-4249. Y. J. Lee, H. C. Kang, J. Hu, J. W. Nichols, Y. S. Jeon, Y. H. Bae, Biomacromol. 2012, 13, 2945-2951.

Q. Chen, X. Liu, J. Chen, J. Zeng, Z. Cheng, Z. Liu, Adv. Mater. 2015, 27, 6820-6827.

M. J. Webber, R. Langer, Chem. Soc. Rev. 2017, 46, 66006620
C. Felip-León, S. Díaz-Oltra, F. Galindo, J. F. Miravet, Chem. Mater. 2016, 28, 7964-7972.

M. Ding, J. Li, H. Tan, Q. Fu, Soft. Matter. 2012, 8, 5414-5428. X.-D. Wang, J. A. Stolwijk, T. Lang, M. Sperber, R. J. Meier, J. Wegener, O. S. Wolfbeis, J. Am. Chem. Soc. 2012, 134 17011-17014.

J. Hu, X. Zhang, D. Wang, X. Hu, T. Liu, G. Zhang, S. Liu, J. Mater. Chem. 2011, 21, 19030-19038.

M. Zhu, D. Lu, S. Wu, Q. Lian, W. Wang, A. H. Milani, Z. Cui, N. T. Nguyen, M. Chen, L. A. Lyon, et al., ACS Macro Lett 2017, 6, 1245-1250.

M. V. Liberti, J. W. Locasale, Trends Bioche. Sci. 2016, 41 , 211-218.

R. Ohgaki, Y. Teramura, D. Hayashi, L. Quan, S. Okuda, S. Nagamori, M. Takai, Y. Kanai, Sci. Rep. 2017, 7: 17484.

M. Anderson, A. Moshnikova, D. M. Engelman, Y. K. Reshetnyak, O. A. Andreev, Proc. Natl. Acad. Sci. U. S. A. 2016, 113, 8177-8181.

G. Ke, Z. Zhu, W. Wang, Y. Zou, Z. Guan, S. Jia, H. Zhang, X Wu, C. J. Yang, ACS Appl. Mater. Interfaces 2014, 6, 1532915334.

Le Ying, N. Xie, Y. Yang, X. Yang, Q. Zhou, B. Yin, J. Huang, K. Wang, Chem. Commun. 2016, 52, 7818-7821.

E. K. Pramod Kumar, K. Almdal, T. L. Andresen, Chem. Commun. 2012, 48, 4776-4778.

E. K. P. Kumar, L. N. Feldborg, K. Almdal, T. L. Andresen, Chem. Mater. 2013, 25, 1496-1501.

E. K. P. Kumar, R. V. Søndergaard, B. Windschiegl, K. Almdal, T. L. Andresen, J. Mat. Chem. B 2014, 2, 6652-6659.

E. K. P. Kumar, R. I. Jølck, T. L. Andresen, Macromol. Rapid Commun. 2015, 36, 1598-1604.

H. Ahn, J. Hong, S. Y. Kim, I. Choi, M. J. Park, ACS Appl. Mater. Interfaces 2015, 7, 704-712.

P. Gong, Y. Yang, H. Yi, S. Fang, P. Zhang, Z. Sheng, G. Gao, D. Gao, L. Cai, Nanoscale 2014, 6, 5416-5424.

S. Chang, X. Wu, Y. Li, D. Niu, Y. Gao, Z. Ma, J. Gu, W. Zhao W. Zhu, H. Tian, et al., Biomaterials 2013, 34, 10182-10190.

A. Fuertes, J. Marisa, J. R. Granja, J. Montenegro, Chem. Commun. 2017, 53, 7861-7871.

I. Gallego, A. Rioboo, J. J. Reina, B. Díaz, Á. Canales, F. J. Cañada, J. Guerra-Varela, L. Sanchez, J. Montenegro, ChemBioChem, 2019, 20, 1400-1409.

M. Juanes, I. Lostalé-Seijo, J. R. Granja, J. Montenegro, Chem. Eur. J. 2018, 24, 10689-10698.

I. Lostalé-Seijo, I. Louzao, M. Juanes, J. Montenegro, Chem. Sci. 2017, 8, 7923-7931.

L. Cao, X. Li, S. Wang, S. Li, Y. Li, G. Yang, Chem. Commun. 2014, 50, 8787-8790.

L. He, X. Yang, F. Zhao, K. Wang, Q. Wang, J. Liu, J. Huang, W. Li, M. Yang, Anal. Chem. 2015, 87, 2459-2465.

Z. Feng, Y. Ma, B. Li, L. He, Q. Wang, J. Huang, J. Liu, X. Yang, K. Wang, Anal. Methods 2019, 11, 2097-2104. P. Wang, C. Zhang, H.-W. Liu, M. Xiong, S.-Y. Yin, Y. Yang, X.-X. Hu, X. Yin, X.-B. Zhang, W. Tan, Chem. Sci. 2017, 8, 8214-8220.

Q. Chen, X. Liu, J. Zeng, Z. Cheng, Z. Liu, Biomaterials 2016 , 98, 23-30.

M. M. C. Bastings, S. Koudstaal, R. E. Kieltyka, Y. Nakano, A C. H. Pape, D. A. M. Feyen, F. J. van Slochteren, P. A. Doevendans, J. P. G. Sluijter, E. W. Meijer, et al., Adv. Healthcare Mater. 2013, 3, 70-78.

Y. Zimenkov, S. N. Dublin, R. Ni, R. S. Tu, V. Breedveld, R. P. Apkarian, V. P. Conticello, J. Am. Chem. Soc. 2006, 128, 6770-6771.

M. T. Fenske, W. Meyer-Zaika, H.-G. Korth, H. Vieker, A Turchanin, C. Schmuck, J. Am. Chem. Soc. 2013, 135, 83428349.

S. Modi, S. M G, D. Goswami, G. D. Gupta, S. Mayor, Y. Krishnan, Nat. Nanotech. 2009, 4, 325-330.

K. Zhou, Y. Wang, X. Huang, K. Luby-Phelps, B. D. Sumer, J. Gao, Angew. Chem. Int. Ed. 2011, 50, 6109-6114. N. S. Lee, G. Sun, W. L. Neumann, J. N. Freskos, J. J. Shieh, R. B. Dorshow, K. L. Wooley, Adv. Mater. 2009, 21, 1344- 
1348.

[120] O. Lustgarten, R. Carmieli, L. Motiei, D. Margulies, Angew. Chem. Int. Ed. 2019, 58, 184-188.

[121] Z. Pode, R. Peri-Naor, J. M. Georgeson, T. Georgeson, V. Kiss, T. Unger, B. Markus, H. M. Barr, L. Motiei, D. Margulies, Nat. Nanotech. 2017, 12, 1161-1168.

H. A. Day, P. Pavlou, Z A. E. Waller, Bioorg. Med. Chem. 2014, 22, 4407-4418.

S. Modi, C. Nizak, S. Surana, S. Halder, Y. Krishnan, Nat. Nanotech. 2013, 8, 459-467.

S. Surana, J. M. Bhat, S. P. Koushika, Y. Krishnan, Nat. Commun. 2011, 2, 340

Y. Li, T. Zhao, C. Wang, Z. Lin, G. Huang, B. D. Sumer, J. Gao, Nat. Commun. 2016, 7, 13214.

I. V. Nesterova, E. E. Nesterov, J. Am. Chem. Soc. 2014, 136, 8843-8846.

A. Idili, A. Vallée-Bélisle, F. Ricci, J. Am. Chem. Soc. 2014, 136, 5836-5839.

S. Halder, Y. Krishnan, Nanoscale 2015, 7, 10008-10012.

N. Narayanaswamy, R. R. Nair, Y. V. Suseela, D. K. Saini, T. Govindaraju, Chem. Commun. 2016, 52, 8741-8744. W. Ma, L. Yan, X. He, T. Qing, Y. Lei, Z. Qiao, D. He, K. Huang, K. Wang, Anal. Chem. 2018, 90, 1889-1896.

J. Huang, Y. He, X. Yang, K. Wang, L. Ying, K. Quan, Y. Yang, B. Yin, Chem. Commun. 2014, 50, 15768-15771.

J. Huang, L. Ying, X. Yang, Y. Yang, K. Quan, H. Wang, N. Xie, M. Ou, Q. Zhou, K. Wang, Anal. Chem. 2015, 87, 87248731.

M. Yang, X. Zhang, H. Liu, H. Kang, Z. Zhu, W. Yang, W. Tan, Anal. Chem. 2015, 87, 5854-5859.

B. Fu, J. Huang, D. Bai, Y. Xie, Y. Wang, S. Wang, X. Zhou, Chem. Commun. 2015, 51, 16960-16963.

H. N. Joo, T. Van Thi Nguyen, H. K. Chae, Y. J. Seo, Bioorg Med. Chem. Lett. 2017, 27, 2415-2419.

Y. Diaz-Fernandez, F. Foti, C. Mangano, P. Pallavicini, S. Patroni, A. Perez-Gramatges, S. Rodriguez-Calvo, Chem. Eur. J. 2006, 12, 921-930.

L. Fu, P. Yuan, Z. Ruan, L. Liu, T. Li, L. Yan, Polym. Chem. 2017, 8, 1028-1038.

J. Hu, G. Liu, C. Wang, T. Liu, G. Zhang, S. Liu, Biomacromol. 2014, 15, 4293-4301.

G. Sun, H. Cui, L. Y. Lin, N. S. Lee, C. Yang, W. L. Neumann, J. N. Freskos, J. J. Shieh, R. B. Dorshow, K. L. Wooley, J. Am Chem. Soc. 2011, 133, 8534-8543.

C. A. Hunter, H. L. Anderson, Angew. Chem. Int. Ed. 2009, 48 7488-7499.

C. Wang, T. Zhao, Y. Li, G. Huang, M. A. White, J. Gao, Adv. Drug. Deliv. Rev. 2016, 113, 87-96.

Y. Wang, K. Zhou, G. Huang, C. Hensley, X. Huang, X. Ma, T. Zhao, B. D. Sumer, R. J. DeBerardinis, J. Gao, Nat. Mater. 2014, 13, 204-212.

C. Wang, Y. Wang, Y. Li, B. Bodemann, T. Zhao, X. Ma, G. Huang, Z. Hu, R. J. DeBerardinis, M. A. White, et al., Nat. Commun. 2015, 6, 8524

T. Zhao, G. Huang, Y. Li, S. Yang, S. Ramezani, Z. Lin, Y. Wang, X. Ma, Z. Zeng, M. Luo, et al., Nat. Biomed. Eng. 2016, 1, 0006

Y. Wang, C. Wang, Y. Li, G. Huang, T. Zhao, X. Ma, Z. Wang, B. D. Sumer, M. A. White, J. Gao, Adv. Mater. 2017, 29, 1603794.

Y. Huang, J. Xing, Q. Gong, L.-C. Chen, G. Liu, C. Yao, Z. Wang, H.-L. Zhang, Z. Chen, Q. Zhang, Nat. Commun. 2019 10, 169-9.
P. J. Pacheco-Liñán, M. Moral, M. L. Nueda, R. Cruz-Sánchez, J. Fernández-Sainz, A. Garzón-Ruiz, I. Bravo, M. Melguizo, J. Laborda, J. Albaladejo, J. Phys. Chem. C 2017, 121 24786-24797.

[148] E. Nakata, Y. Yukimachi, Y. Nazumi, Y. Uto, H. Maezawa, T. Hashimoto, Y. Okamoto, H. Hori, Chem. Commun. 2010, 46, 3526-3528.

[149] E. Nakata, Y. Yukimachi, Y. Nazumi, M. Uwate, H. Maseda, Y. Uto, T. Hashimoto, Y. Okamoto, H. Hori, T. Morii, RSC Adv. 2014, 4, 348-357.

[150] T. Jing, L. Yan, Talanta 2017, 170, 185-192.

[151] Y. Liu, Z. Qu, H. Cao, H. Sun, Y. Gao, X. Jiang, ACS Nano 2017, 11, 12446-12452.

[152] E. S. Cho, S. W. Hong, W. H. Jo, Macromol. Rapid Commun. 2008, 29, 1798-1803.

[153] J. Luo, Z. Xie, J. W. Y. Lam, L. Cheng, H. Chen, C. Qiu, H. S. Kwok, X. Zhan, Y. Liu, D. Zhu, et al., Chem. Commun. 2001 18, 1740-1741.

[154] H. Lu, B. Xu, Y. Dong, F. Chen, Y. Li, Z. Li, J. He, H. Li, W. Tian, Langmuir 2010, 26, 6838-6844.

[155] J. Mei, N. L. C. Leung, R. T. K. Kwok, J. W. Y. Lam, B. Z. Tang, Chem. Rev. 2015, 115, 11718-11940.

[156] S. Chen, Y. Hong, Y. Liu, J. Liu, C. W. T. Leung, M. Li, R. T. K. Kwok, E. Zhao, J. W. Y. Lam, Y. Yu, et al., J. Am. Chem. Soc. 2013, 135, 4926-4929.

[157] G. Feng, R. T. K. Kwok, B. Z. Tang, B. Liu, Appl. Phys. Rev. 2017, 4, DOI 10.1063/1.4984020

[158] L. Shi, Y. Liu, Q. Wang, T. Wang, Y. Ding, Y. Cao, Z. Li, H. Wei, Analyst 2018, 143, 741-746.

[159] Q. Qi, Y. Li, X. Yan, F. Zhang, S. Jiang, J. Su, B. Xu, X. Fu, L. Sun, W. Tian, Polym. Chem. 2016, 7, 5273-5280.

[160] P. Song, X. Chen, Y. Xiang, L. Huang, Z. Zhou, R. Wei, A. Tong, J. Mater. Chem. 2011, 21, 13470-13475.

[161] Q. Feng, Y. Li, L. Wang, C. Li, J. Wang, Y. Liu, K. Li, H. Hou, Chem. Commun. 2016, 52, 3123-3126.

[162] M. Shellaiah, T. Simon, V. Srinivasadesikan, C.-M. Lin, K. W Sun, F.-H. Ko, M.-C. Lin, H.-C. Lin, J. Mat. Chem. C 2016, 4 2056-2071.

[163] X. Ma, J. Cheng, J. Liu, X. Zhou, H. Xiang, New. J. Chem. 2014, 39, 492-500.

[164] X. Zhang, S. Rehm, M. M. Safont-Sempere, F. Würthner, Nat. Chem. 2009, 1, 623-629.

[165] Z. Duan, Y.-J. Gao, Z.-Y. Qiao, S. Qiao, Y. Wang, C. Hou, L. Wang, H. Wang, Nanotech. 2015, 26, 1-11.

[166] Z. Yang, W. Qin, J. W. Y. Lam, S. Chen, H. H. Y. Sung, I. D. Williams, B. Z. Tang, Chem. Sci. 2013, 4, 3725-3730.

Z. Zhou, F. Gu, L. Peng, Y. Hu, Q. Wang, Chem. Commun. 2015, 51, 12060-12063 Y. Bao, H. De Keersmaecker, S. Corneillie, F. Yu, H. Mizuno G. Zhang, J. Hofkens, B. Mendrek, A. Kowalczuk, M. Smet, Chem. Mater. 2015, 27, 3450-3455.

[169] Y. Zhang, O. Xie, J. B. Robertson, C. H. Johnson, PLoS ONE 2012, 7, e43072-11.

[170] S. Burgstaller, H. Bischof, T. Gensch, S. Stryeck, B. Gottschalk, J. Ramadani-Muja, E. Eroglu, R. Rost, S. Balfanz, A. Baumann, et al., ACS Sens. 2019, 4, 883-891.

[171] P. Anees, K. V. Sudheesh, P. Jayamurthy, A. R. Chandrika, R.

[172] V. Omkumar, A. Ajayaghosh, Chem. Sci. 2016, 7, 6808-6814 Bioanal. Chem. 2017, 409, 5073-5080. 
